\title{
A Closed-Form Solution for the Analysis of Antifreeze Disease Fortification Length in a Permafrost Tunnel
}

\author{
Jun-wei Zhang $\mathbb{D}^{1}{ }^{1}$ Yi-chong Zhang, ${ }^{1}$ Lei Li, ${ }^{1}$ Bing-feng Liu, ${ }^{1}$ and Zhi-rong Mei ${ }^{2}$ \\ ${ }^{1}$ School of Geoscience and Technology, Southwest Petroleum University, Sichuan, Chengdu 610500, China \\ ${ }^{2}$ China Academy of Railway Sciences, Beijing 100086, China \\ Correspondence should be addressed to Jun-wei Zhang; zjwcq@lzb.ac.cn
}

Received 7 December 2019; Revised 13 January 2020; Accepted 20 January 2020; Published 18 February 2020

Academic Editor: Zaobao Liu

Copyright $(2020$ Jun-wei Zhang et al. This is an open access article distributed under the Creative Commons Attribution License, which permits unrestricted use, distribution, and reproduction in any medium, provided the original work is properly cited.

Frost damage in permafrost tunnels is very common, and this can have a negative influence on traffic. The most serious frost damage typically occurs at a certain length from the tunnel opening. Thus the antifreeze measures of the lining structure in this area need to be strengthened. In this study, the antifreeze disease fortification length for permafrost tunnels is determined from heat transfer and mathematical physics equations by the theoretical analysis method. The temperature distribution characteristics of the lining along the tunnel axis under the influence of the tunnel depth, the tunnel radius, the wind velocity at the tunnel opening, and the thermal conductivity of the insulation layer are analysed. The results show that the longitudinal temperature characteristics in the tunnel axis are influenced by many factors. The proposed antifreeze disease length of the permafrost tunnel was found to be approximately 31 times of the tunnel diameter, which agrees with the results of the numerical simulation. It verifies the rationality of the theoretical calculation. This value, 31 times of the tunnel diameter, can be used as a reference for the design of the tunnel antifreeze disease fortification length.

\section{Introduction}

A large number of tunnels will be built in global permafrost regions in the future. This will be done to meet the requirements of national transportation infrastructure development. However, there will always be various frost damage problems [1-4], such as cracking of tunnel opening, pavement freezing (Figure 1(a)), drainage ditch freezing (Figure 1(b)), lining cracking, ice hanging on vaults, ice hanging on side walls, and other problems, during the operation of tunnels, as shown in Table 1. The groundwater, the low temperature, and the frost heave force are three important factors that result in frost damage [1, 2, 4-12]. The most important reason for this damage is that the tunnels in the cold regions are built in the complex geological environments with the freeze-thaw cycles [9]. In addition, the freeze damage of tunnels under the extreme weather and the low temperatures is also related to the human factors, such as insufficient waterproofing, poor drainage design, and water leakage. The reasons are no consideration of the frost heave and the invalidation of thermal insulation material $[1,13,14]$, as shown in Table 2 . The abovementioned frost damage will seriously threaten the structural safety of a tunnel and decrease the maintenance and the service life. The existing research results show that the freeze damage is closely related to the temperature distribution characteristics in a tunnel and the temperature distribution characteristics of the surrounding rock around tunnel structures. Therefore, this can provide a theoretical basis for the antifreeze measures taken to prevent the tunnel frost damage. Hence, there is a need to study the temperature distribution characteristics of tunnels and the surrounding rocks around the tunnel lining in permafrost.

The temperature monitoring results in the permafrost tunnel indicate that the lining structure within a certain distance from the tunnel opening was more prone to freeze damage under a freeze-thaw cycle than the other sections of the tunnel $[2,5,8,9,11,15,16]$. Thus, it is necessary to strengthen the lining structure and the antifreeze measures within a certain distance from the tunnel opening 


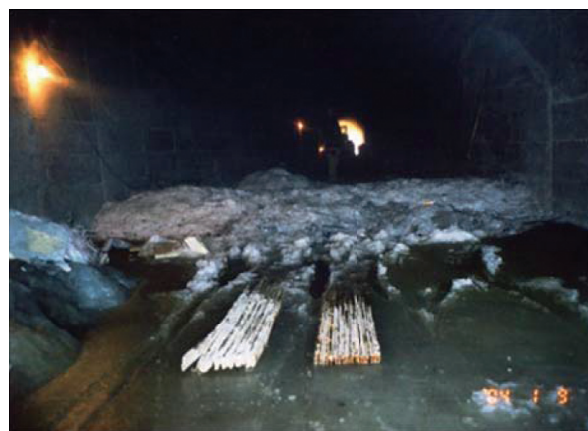

(a)

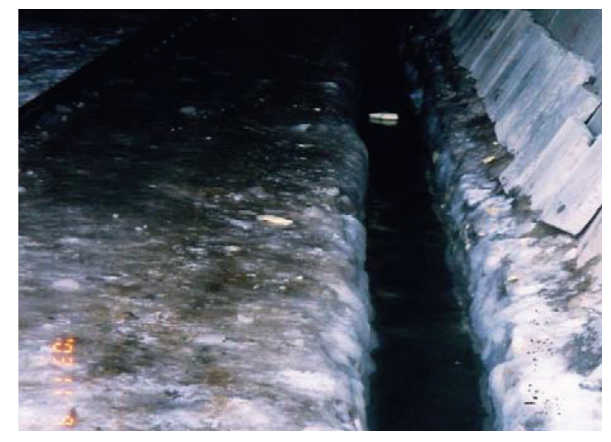

(b)

FIgURE 1: Frost damage in a permafrost tunnel: (a) pavement freezing; (b) drainage ditch freezing.

TABLE 1: Frost damage characteristics in permafrost tunnels [1].

\begin{tabular}{|c|c|c|c|c|c|c|c|}
\hline Tunnel name & $\begin{array}{c}\text { Icy } \\
\text { pavement }\end{array}$ & $\begin{array}{c}\text { Frozen drainage } \\
\text { ditches }\end{array}$ & $\begin{array}{l}\text { Lining } \\
\text { cracking }\end{array}$ & $\begin{array}{c}\text { Ice hanging on } \\
\text { arch }\end{array}$ & $\begin{array}{l}\text { Tunnel opening } \\
\text { cracking }\end{array}$ & $\begin{array}{l}\text { Spalling of } \\
\text { lining }\end{array}$ & $\begin{array}{l}\text { Water } \\
\text { leakage }\end{array}$ \\
\hline Tiziling & $\checkmark$ & & $\checkmark$ & & & & \\
\hline Qidaoliang & $\checkmark$ & $\checkmark$ & $\checkmark$ & & & & \\
\hline Dabanshan & $\checkmark$ & & $\checkmark$ & $\checkmark$ & & & $\checkmark$ \\
\hline Lingding & $\checkmark$ & $\checkmark$ & $\checkmark$ & $\checkmark$ & & $\sqrt{ }$ & $\checkmark$ \\
\hline Kuixian & & & & & & $\sqrt{ }$ & \\
\hline Xinganling & $\checkmark$ & & & & & & \\
\hline Yuximole & $\checkmark$ & & $\checkmark$ & $\checkmark$ & & & \\
\hline Beiweizi & $\checkmark$ & & & & & & \\
\hline Baikaer & & & $\checkmark$ & $\checkmark$ & & $\checkmark$ & \\
\hline No. 2 Xiluoqi & & & $\checkmark$ & $\checkmark$ & & $\checkmark$ & \\
\hline Yaling & & & & & $\checkmark$ & & \\
\hline Nenlin & $\checkmark$ & & $\checkmark$ & $\checkmark$ & & $\checkmark$ & \\
\hline No. 2 Cuiling & $\checkmark$ & & $\checkmark$ & $\checkmark$ & & $\checkmark$ & \\
\hline Kunlunshan & & $\checkmark$ & & $\checkmark$ & & $\checkmark$ & $\checkmark$ \\
\hline Nanshan & & $\checkmark$ & & & & & $\checkmark$ \\
\hline Qingshanli & & $\checkmark$ & & & & & $\checkmark$ \\
\hline No. 1 Songyue & & $\checkmark$ & & & & & $\checkmark$ \\
\hline Aolaling & & & & & & & \\
\hline Mijiang & $\checkmark$ & & $\checkmark$ & $\checkmark$ & & & $\checkmark$ \\
\hline Guanjiao & & & $\checkmark$ & $\checkmark$ & & & $\checkmark$ \\
\hline Habutegai & & & $\checkmark$ & & & & \\
\hline No. 2 & & & & & & & \\
\hline Hujiriyan & & & $\checkmark$ & & & & \\
\hline Yongan & & & & $\checkmark$ & & & \\
\hline Fenshuiling & & & $\checkmark$ & $\checkmark$ & & & $\checkmark$ \\
\hline No. 2 Tianshan & $\checkmark$ & & & $\checkmark$ & & & \\
\hline
\end{tabular}

$[7,15,17-19]$. These areas can be optimized with an investment. Such an investment would reduce the cost of frost damage treatment by a comprehensive understanding of the frost-resistant fortification location and by the use of reasonable thermal insulation materials. Thus, an antifreeze study based on the location of this optimal temperature field in tunnels has become a hot research topic.

For this purpose, Chen and Luo [7] conducted an equivalent thickness-changing algorithm, meteorological analysis method, and finite element simulation method to calculate the antifreeze thickness of frozen soil in a tunnel. They measured and analyzed the temperature field and developed a temperature variation law for the inside and outside of the tunnel using time, tunnel length, and tunnel depth. They also obtained a variation law for the maximum freeze depth with length $[6,11,12,20,21]$. Xu et al. [16] studied the variation law of the temperature field in the Tianshan tunnel in the second line of Tucu, and they studied the selection problem for the insulation parameters based on a field test of the surrounding rock temperature field. Zhichun et al. [6] conducted a long-term systematic observation and analysis of the temperature inside and outside the tunnel during the construction of the Fenghuoshan tunnel. This study not only provided a scientific basis for tunnel construction decision-making but also provided much reference information for subsequent research work of the tunnel. After the 1980s, scholars from various countries began to study the longitudinal temperature field characteristics of tunnels, and they considered the influence of phase transitions [22-25]. Simplified analytical solutions 
TABle 2: Causes of tunnel frost damage [1].

\begin{tabular}{|c|c|c|c|c|c|c|}
\hline Tunnel name & $\begin{array}{l}\text { Insufficient waterproofing } \\
\text { and drainage design }\end{array}$ & $\begin{array}{l}\text { Water } \\
\text { leakage }\end{array}$ & $\begin{array}{l}\text { Extreme } \\
\text { weather }\end{array}$ & $\begin{array}{c}\text { Low } \\
\text { temperature }\end{array}$ & $\begin{array}{l}\text { No consideration of } \\
\text { frost heave }\end{array}$ & $\begin{array}{l}\text { Invalidation of thermal } \\
\text { insulation material }\end{array}$ \\
\hline Tiziling & $\checkmark$ & & & & & \\
\hline Qidaoliang & $\checkmark$ & & & & & \\
\hline Dabanshan & & & & & $\checkmark$ & \\
\hline Lingding & & $\checkmark$ & & & & \\
\hline Kuixian & $\checkmark$ & & & & & \\
\hline Xinganling & & $\checkmark$ & & & & \\
\hline Yuximole & & $\checkmark$ & & & & \\
\hline Beiweizi & & & $\checkmark$ & & & \\
\hline Baikaer & & & & & & $\checkmark$ \\
\hline No. 2 Xiluoqi & & & & & & $\checkmark$ \\
\hline Yaling & & & & & $\checkmark$ & \\
\hline Nenlin & & & & & $\checkmark$ & \\
\hline No. 2 Cuiling & & & & & $\checkmark$ & \\
\hline Kunlunshan & & $\checkmark$ & & & & \\
\hline Nanshan & $\checkmark$ & & & & & \\
\hline Qingshanli & $\checkmark$ & & & & & \\
\hline No. 1 & & & & & & \\
\hline Songyue & $\checkmark$ & & & & & \\
\hline Aolaling & $\checkmark$ & & & & & \\
\hline Mijiang & & $\checkmark$ & & & & \\
\hline Guanjiao & & & & & & \\
\hline Habutegai & & & & & & \\
\hline No. $2^{\circ}$ & & & & & & \\
\hline Hujiriyan & & & & $\checkmark$ & & \\
\hline Yongan & & & & $\checkmark$ & & \\
\hline Fenshuiling & & $\checkmark$ & & & & \\
\hline No. 2 & & & & & & \\
\hline Tianshan & & $\checkmark$ & & & & \\
\hline
\end{tabular}

and finite element software were used to analyze the temperature field of frozen soil tunnels.

It should be noted that measures to prevent frost damage in tunnels have also been studied. For example, Chen and Luo [7] examined the effect of plastic insulation to prevent icing in railway tunnels. Based on experiments in the Dagushan Tunnel in Qinghai, the effects of various insulation measures on the frozen soil in tunnels were comprehensively analyzed and evaluated by Yuanming et al. $[5,26]$ during the construction of insulation layers, installation of insulation doors, and construction of antisnow sheds outside the caves. Gang et al. [15] studied the thermal insulation principle of the off-wall lining structure in a cold tunnel. Yuanming et al. [5] analyzed field observational data and came to the following conclusions: compared with the installation of snow sheds, the installation of an insulated door had a better insulation effect. In the former Soviet Union, a tunnel was heated using a tubular electric heater, and a ditch was insulated with a new type of high-efficiency insulation material [1]. A thermal insulation material between the shotcrete and the lining in the Hohhot tunnel in Hokkaido was positioned to prevent geothermal heat release and to maintain the temperature around the tunnel lining from falling below the freezing point [10, 19, 27-31].

However, the above research did not focus on air temperature variations in a certain length from the tunnel opening along the tunnel axis, nor did they consider the influence of thermal insulation and freezing protection measures on temperature variations along the tunnel axial direction. For the sequential convenience of research, a certain length from the tunnel opening is defined as the antifreeze disease fortification length in advance. The antifreeze disease length of a tunnel will have great significance for fortification measures and engineering practice according to the temperature variation characteristics in the axial direction of a tunnel. The air temperature distribution characteristics in the tunnel lining inner wall and the surrounding rock behind the lining in permafrost tunnels are studied, especially the longitudinal air temperature field in the axial direction of a tunnel based on the theory of heat transfer. In addition, the closed-form solution for the analysis of the longitudinal temperature distribution in a tunnel and behind the surrounding rock in the axial direction of a tunnel is derived. By analyzing the closed-form solution for the longitudinal temperature distribution in a tunnel and the surrounding rock behind the lining in the axial direction of a tunnel, the antifreeze disease length in a permafrost tunnel opening section can be determined. Furthermore, the results obtained from analytical solutions are generally required for validation and calibration of numerical methods. The closed-form solution of the antifreeze disease length can provide a new method for developing the thermal insulation layer design of a permafrost tunnel for the tunnel opening section in the future. 


\section{Temperature Field Research Based on Thermodynamics}

2.1. Basic Assumptions. To simplify the closed-form solution for the analysis of antifreeze disease fortification length in the permafrost tunnel, the following assumptions need to be considered:

(1) The cross section of the tunnel is circular

(2) The thermal resistance contact between the surrounding rock and the lining should be ignored, and the effect of thermal resistance contact on heat transfer is not considered

(3) The temperature inside the tunnel only considers the direction along the tunnel axis

(4) The air flow rate in the tunnel is constant, and only the air flow rate along the longitudinal direction of the tunnel is considered, regardless of the air flow rate in other directions

(5) The phase change effect on the temperature field of the tunnel should not be considered

(6) The air in the tunnel is an incompressible Newtonian fluid

(7) The air temperature in the tunnel is constant, and there is no internal heat source

(8) The heat generated by viscous dissipation is negligible

2.2. Cross-Sectional Temperature Field Calculation of a Tunnel. The surrounding rock temperature around permafrost tunnels is usually divided into a variable temperature zone, a constant temperature zone, and a warming zone successively from the ground top to bottom, as shown in Figure 2. Assuming that the tunnel is in a warming zone, the composite structure consisting of shotcrete, an insulation layer, and the lining is regarded as a structure, without considering the insulation layer.

To solve the problem of heat conduction between the tunnel lining and the surrounding rock, the heat conduction differential equation based on heat transfer theory can be obtained [32]:

$$
\left\{\begin{array}{l}
k_{1}\left(\frac{\partial^{2} T_{1}}{\partial r^{2}}+\frac{1}{r} \frac{\partial T_{1}}{\partial r}\right)=\frac{\partial T_{1}}{\partial t} \\
k_{2}\left(\frac{\partial^{2} T_{2}}{\partial r^{2}}+\frac{1}{r} \frac{\partial T_{2}}{\partial r}\right)=\frac{\partial T_{2}}{\partial t} \\
k_{3}\left(\frac{\partial^{2} T_{3}}{\partial r^{2}}+\frac{1}{r} \frac{\partial T_{3}}{\partial r}\right)=\frac{\partial T_{3}}{\partial t} \\
k_{4}\left(\frac{\partial^{2} T_{4}}{\partial r^{2}}+\frac{1}{r} \frac{\partial T_{4}}{\partial r}\right)=\frac{\partial T_{4}}{\partial t}
\end{array}\right.
$$

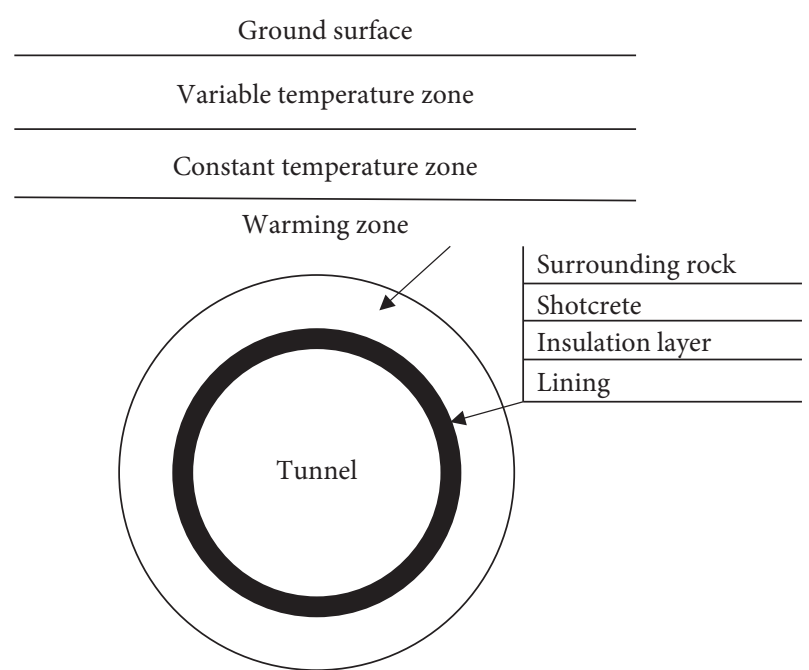

Figure 2: Cross-section distribution diagram of the surrounding rock, the shotcrete, the insulation layer, and the lining.

where $k_{1}, k_{2}, k_{3}$, and $k_{4}$ are the thermal diffusivity of the lining, the thermal diffusivity of the insulation layer, the thermal diffusivity of the shotcrete, and the thermal diffusivity of the surrounding rock, respectively, and $T_{1}, T_{2}, T_{3}$, and $T_{4}$ represent the temperature of the lining, the temperature of the insulation layer, the temperature of the shotcrete, and the temperature of the surrounding rock, respectively.

The cross-sectional temperature field calculation inside the tunnel lining and around the tunnel lining can be determined when $k_{2}=0$. Convective heat transfer occurs between the air and the tunnel wall. According to the third type of boundary conditions of the heat transfer heat conduction problem, the following formula can be obtained:

$$
\lambda_{1} \frac{\partial T_{1}}{\partial r}\left(z, r_{0} t\right)=-\alpha\left[T_{1}\left(z, r_{0} t\right)-f(z, t)\right],
$$

where $f(z, t)$ is the air temperature variation inside the tunnel with the tunnel length and time, ${ }^{\circ} \mathrm{C} ; r_{0}$ is the radius of the tunnel, $\mathrm{m} ; \alpha_{1}$ is the convection heat transfer coefficient of the air inside the lining wall, $\mathrm{W} /\left(\mathrm{m}^{2} \cdot{ }^{\circ} \mathrm{C}\right)$; and $\lambda_{1}$ is the thermal conductivity of the lining.

It should be emphasized that the air temperature inside the tunnel variation with tunnel length and time is

$$
f(z, t)=T_{A}(z)+G(z) \cos (\omega t+\varphi),
$$

where $T_{A}(z)$ is the annual air average temperature function in the tunnel; $G(z)$ is the temperature amplitude function of the air inside the tunnel; $\omega$ is the temperature distribution function angular velocity; and $\varphi$ is the temperature distribution function phase.

The contact conditions between the lining and the surrounding rock are then obtained:

$$
\left\{\begin{array}{l}
T_{1}\left(z, r_{1}, t\right)=T_{2}\left(z, r_{1}, t\right) \\
T_{2}\left(z, r_{2}, t\right)=T_{3}\left(z, r_{2}, t\right), \\
T_{3}\left(z, r_{3}, t\right)=T_{4}\left(z, r_{3}, t\right)
\end{array}\right.
$$


where $r_{1}, r_{2}, r_{3}$, and $r_{4}$ represent the outside radius of the tunnel lining, the radius of the insulation layer, the radius of the shotcrete, and the radius of the variable temperature zone, respectively.

Based on equation (4), the following contact conditions are obtained:

$$
\left\{\begin{array}{l}
-\lambda_{1} \frac{\partial T_{1}\left(z, r_{1}, t\right)}{\partial r}=-\lambda_{2} \frac{\partial T_{2}\left(z, r_{1}, t\right)}{\partial r} \\
-\lambda_{2} \frac{\partial T_{2}\left(z, r_{2}, t\right)}{\partial r}=-\lambda_{3} \frac{\partial T_{3}\left(z, r_{2}, t\right)}{\partial r} \\
-\lambda_{3} \frac{\partial T_{3}\left(z, r_{3}, t\right)}{\partial r}=-\lambda_{4} \frac{\partial T_{4}\left(z, r_{3}, t\right)}{\partial r}
\end{array}\right.
$$

where $\lambda_{1}, \lambda_{2}, \lambda_{3}$, and $\lambda_{4}$ are the thermal conductivity of the lining, the insulation layer, the shotcrete, and the surrounding rock, respectively.

The boundary conditions of the tunnel surrounding rock are as follows:

$$
\left\{\begin{array}{l}
T_{4}\left(r_{4}, 0\right)=T_{0}, \\
T_{0}=T_{B}+\left(H-h_{b}-h_{h}-h_{w}\right) K^{\prime}
\end{array}\right.
$$

where $T_{0}$ is the temperature in the warming zone; $T_{B}$ is the temperature in the variable temperature zone; $H$ is the cover depth of the tunnel; $h_{b}$ is the height of the variable temperature zone; $h_{h}$ is the height of the constant temperature zone; $h_{w}$ is the influence depth of the tunnel surrounding rock; and $K$ is the ground temperature gradient of the surrounding rock.

According to the first type of boundary condition and the superposition principle of heat conduction problem, the temperature field of the surrounding rock around the tunnel lining is superposed by a transient temperature field and a steady temperature field. Because both the air temperature inside the tunnel and the temperature of the surrounding rock around the tunnel lining vary with both the tunnel radius and the tunnel length, the temperature formula of the lining and the surrounding rock is assumed to be

$$
\left\{\begin{array}{l}
T_{11}=g_{1}(r) \times G(z) \times F_{1}(t), \\
T_{12}=g_{2}(r) \times G(z) \times F_{2}(t),
\end{array}\right.
$$

where $T_{11}$ and $T_{12}$ represent the transient temperatures of the lining and the surrounding rock, respectively.

Therefore, according to Euler's formula, the convenient and initial conditions are brought into equation (7) by solving the Bessel equation using virtual variables. In addition, the temperature formula of the tunnel wall without the insulation layer is obtained using equations (2)-(6):

$$
\left\{\begin{array}{l}
T_{1}\left(r_{0}\right)=T_{0} A\left(T_{0}-T_{A}\right)\left(\ln \frac{r_{0}}{r_{1}}+\frac{\lambda_{1}}{\lambda_{2}} \ln \frac{r_{1}}{r_{2}}\right)+g_{1}\left(r_{0}\right) \times G(z) \times \sin \left(\omega t+\varphi_{1}\right), \\
A=\frac{1}{\ln r_{1} / r_{0}-\lambda_{1} / \lambda_{2} \ln r_{1} / r_{2}+\lambda_{1} / r_{0} \alpha_{1}},
\end{array}\right.
$$

where $r_{1}$ and $r_{2}$ are the radii of the lining and the surrounding rock, respectively.

According to the heat conduction differential equation (1) of the heat transfer, the air in the tunnel and the tunnel wall undergo convective heat transfer:

$$
-\lambda_{1} \frac{\partial T_{1}}{\partial_{r}}\left(z, r_{0}, t\right)=-\alpha_{1}\left[T_{1}\left(z, r_{0}, t\right)-f(z, t)\right],
$$

where $T_{3}$ is the temperature of the lining and $R_{0}$ is the tunnel radius.
The temperature inside the tunnel varies with the axial length and time. Hence, the equation for the temperature inside the tunnel can be assumed to be equation (7). According to the contact conditions between the lining and the surrounding rock and the boundary conditions of the surrounding rock, the temperature field of the surrounding rock around the tunnel lining can be obtained by superimposing the transient temperature field and the steady temperature field:

$$
\left\{\begin{array}{l}
T_{1}\left(r_{0}\right)=T_{0}+B\left(T_{0}-T_{A}\right)\left(\ln \frac{r_{0}}{r_{1}}+\frac{\lambda_{1}}{\lambda_{4}} \ln \frac{r_{3}}{r_{4}}+\frac{\lambda_{1}}{\lambda_{3}} \ln \frac{r_{2}}{r_{3}}+\frac{\lambda_{1}}{\lambda_{2}} \ln \frac{r_{1}}{r_{2}}\right)+g_{1}\left(r_{0}\right) \times G(z) \times \sin \left(\omega t+\varphi_{3}\right) \\
\mathrm{B}=\frac{1}{\ln \left(r_{0} / r_{1}\right)-\left(\lambda_{1} / \lambda_{2}\right) \ln \left(r_{1} / r_{2}\right)-\left(\lambda_{1} / \lambda_{3}\right) \ln \left(r_{2} / r_{3}\right)-\left(\lambda_{1} / \lambda_{4}\right) \ln \left(r_{3} / r_{4}\right)+\left(\lambda_{1} / r_{0} \alpha_{1}\right)}
\end{array}\right.
$$


2.3. Profile Temperature Field Calculation. According to the conservation of energy, the following formula can be obtained using Figure 3:

$$
\begin{aligned}
\Phi+Q_{\mathrm{sf}}= & \frac{\partial U}{\partial t}+q_{1}\left(h+\frac{1}{2} v^{2}+g z\right)_{\mathrm{out}} \\
& -q_{2}\left(h+\frac{1}{2} v^{2}+g z\right)_{\mathrm{in}}+W,
\end{aligned}
$$

where $\Phi$ is the heat entering the differential element through heat conduction; $Q_{\mathrm{sf}}$ is the heat of the microair and tunnel lining convection into the differential element; $U$ is the thermodynamic energy of the microbody; and $W$ is the work done by the fluid.

By considering that the change in potential energy and kinetic energy is very low when air passes through the differential element in the tunnel, these can be neglected:

$$
\Phi+Q_{\mathrm{sf}}=\frac{\partial U}{\partial t}+q_{1}(h)_{\text {out }}-q_{2}(h)_{\text {in }} .
$$

The thermodynamic increment of the differential element in unit time is

$$
\frac{\partial U}{\partial t}=\rho c_{p} M \frac{\partial T_{f}}{\partial t} \mathrm{~d} t \mathrm{~d} s,
$$

where $\rho$ is the air density; $c_{p}$ is the air heat capacity; $M$ is the cross-sectional area of the tunnel; and $T_{f}$ is the average air temperature in the tunnel.

Because Baker's value of air is very large in the same time, $d_{t}$, the energy of the inflowing differential element between the tunnel wall and the differential element due to the convective heat transfer can be obtained:

$$
Q_{\mathrm{sf}}=\alpha_{1}\left(T_{s}-T_{f}\right) P \mathrm{~d} s \mathrm{~d} t,
$$

where $\alpha_{1}$ is the convection heat transfer coefficient of the air inside the lining wall; $T_{s}$ is the temperature in the tunnel wall; $T_{f}$ is the temperature of the air in the tunnel; and $P$ is the perimeter of the tunnel.

The ultimate simplified energy conservation equation is as follows:

$$
\frac{\partial T_{f}}{\partial t}+\frac{\partial T_{f}}{\partial s} V_{s}=\frac{2 \alpha_{1}}{\rho c_{p} r_{0}}\left(T_{s}-T_{f}\right)
$$

\subsubsection{Closed-Form Solution of Longitudinal Temperature} Field without the Thermal Insulation Layer. When the tunnel is not laid with insulation, the differential equation for the annual average air temperature is

$$
\begin{aligned}
T_{A}(z)= & T_{0}+\left(T_{J}-T_{0}\right) \operatorname{EXP}\left(-\frac{2 \alpha_{1}}{V_{f} \rho c_{p} r_{0}}\left(A \left(\ln \frac{r_{0}}{r_{1}}\right.\right.\right. \\
& \left.\left.\left.+\frac{\lambda_{1}}{\lambda_{2}} \ln \frac{r_{1}}{r_{2}}\right)+1\right) z\right),
\end{aligned}
$$

where $T_{J}$ is the air average temperature at the tunnel opening.

The differential equation of annual average amplitude is

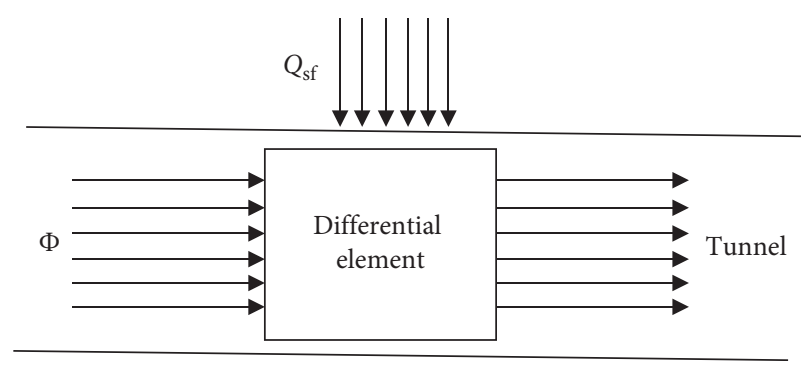

FIgURE 3: Axial heat transfer model of air in the tunnel.

$$
\begin{array}{r}
V_{f} \frac{\mathrm{d} G(z)}{\mathrm{d} z} \cos (\omega t+\varphi)-G_{1}(z) \omega \sin (\omega t+\varphi) \\
\quad=-\frac{2 \alpha_{1}}{\rho c_{p} r_{0}}\left(G_{1}(z) \cos (\omega t+\varphi)-T_{11}\left(r_{0}, z\right)\right) .
\end{array}
$$

The temperature field distribution formula of the tunnel wall without the insulation layer is obtained using Euler's equation:

$$
\begin{aligned}
T_{1}\left(r_{0}\right)= & T_{0}+A\left(T_{0}-T_{A}\right)\left(\ln \frac{r_{0}}{r_{1}}+\frac{\lambda_{1}}{\lambda_{2}} \ln \frac{r_{1}}{r_{2}}\right) \\
& +g_{1}\left(r_{0} \times \sin \left(\omega t+\varphi_{1}\right) \times K_{1}(z) \operatorname{EXP}\left(-i\left(\frac{\omega}{V_{f}}\right.\right.\right. \\
& \left.\left.+\frac{2 \alpha_{1} g_{1}\left(r_{0}\right) \cos \varphi_{1}}{V_{f} \rho c_{p} r_{0}}\right) z\right), \\
K_{1}(z)= & G_{0} \operatorname{EXP} \frac{\left(2 \alpha_{1}-2 \alpha_{1} g_{1}\left(r_{0}\right) \sin \varphi_{1}\right) z}{V_{f} \rho c_{p} r_{0}},
\end{aligned}
$$

where $G_{0}$ is the temperature amplitude at the tunnel opening.

\subsubsection{Closed-Form Solution of Longitudinal Temperature} Field with the Thermal Insulation Layer. When the insulation layer is laid in the tunnel, the annual air average temperature is obtained using the differential equation of the annual average air temperature and the boundary conditions:

$$
\begin{aligned}
T_{A}(z)= & T_{0}+\left(T_{J}-T_{0}\right) \operatorname{EXP}\left(-\frac{2 \alpha_{1}}{V_{f} \rho c_{p} R_{0}}\left(B \left(\ln \frac{R_{0}}{R_{1}}+\frac{\lambda_{1}}{\lambda_{4}} \ln \frac{R_{3}}{R_{4}}\right.\right.\right. \\
& \left.\left.\left.+\frac{\lambda_{1}}{\lambda_{3}} \ln \frac{R_{2}}{R_{3}}+\frac{\lambda_{1}}{\lambda_{2}} \ln \frac{R_{1}}{R_{2}}\right)+1\right) z\right) .
\end{aligned}
$$

The solution of the annual temperature amplitude is 


$$
\begin{aligned}
& \left\{G(z)=G_{0} \operatorname{EXP}\left(\frac{\left(2 \alpha_{1}-2 \alpha_{1} g_{3}\left(R_{0}\right) \sin \varphi_{3}\right) z}{V_{f} \rho c_{p} R_{0}}\right)\right. \\
& \quad \times \operatorname{EXP}\left(i(\omega t+\varphi)-i\left(\frac{\omega}{V_{f}}+\frac{2 \alpha_{1} g_{3}\left(R_{0}\right) \cos \varphi_{3}}{V_{f} \rho c_{p} R_{0}}\right) z\right) \\
& \left\{K(z)=G_{0} \operatorname{EXP}\left(\frac{\left(2 \alpha_{1}-2 \alpha_{1} g_{3}\left(R_{0}\right) \sin \varphi_{3}\right) z}{V_{f} \rho c_{p} R_{0}}\right)\right.
\end{aligned}
$$

Therefore, the temperature field distribution characteristics inside the tunnel lining with the insulation layer are as follows:

$$
\begin{aligned}
T_{3}\left(r_{0}\right)= & T_{0}+A\left(T_{0}-T_{A}\right)\left(\ln \frac{r_{0}}{r_{1}}+\frac{\lambda_{1}}{\lambda_{4}} \ln \frac{r_{3}}{r_{4}}+\frac{\lambda_{1}}{\lambda_{3}} \ln \frac{r_{2}}{r_{3}}+\frac{\lambda_{1}}{\lambda_{2}} \ln \frac{r_{1}}{r_{2}}\right) \\
& +g_{3}\left(r_{0}\right) K(z) \operatorname{EXP}\left(-i\left(\frac{\omega}{V_{f}}+\frac{2 \alpha_{1} g_{3}\left(r_{0}\right) \cos \varphi_{3}}{V_{f} \rho c_{p} R_{0}}\right) z\right) \\
& \cdot \sin \left(\omega t+\varphi_{3}\right) .
\end{aligned}
$$

\section{Resolution of Antifreezing Fortification Length in the Tunnel}

\subsection{Determination of Theoretical Calculation Parameters.} To facilitate the theoretical calculation, the thermodynamic parameters of the surrounding rock were converted into uniform parameters. In addition, the air velocity in the radial direction and the axial direction of the tunnel were assumed to be the same. It was assumed that a velocity value in the air velocity range of the tunnel was used in the tunnel for the numerical calculation. This theoretical calculation uses the Fenghuoshan tunnel from the Qinghai-Tibet Railway as an example and uses the relevant parameters of the Fenghuoshan tunnel for calculation and analysis, as shown in Table 3.

3.2. Analysis of Theoretical Calculation Results. Both the average air temperature distribution trend in the tunnel and the temperature distribution trend of the inner surface in the tunnel lining are primarily affected by the average temperature function, $H(z)$, and the temperature amplitude function, $K(z)$. The average air temperature distribution trend in the tunnel described by (20) is identical with the temperature distribution trend of the inner surface of the tunnel lining described by (21). Both the functions, $H(z)$, average temperature distribution characteristics and the temperature amplitude function, $K(z)$, are used to analyze the temperature variation from the tunnel opening in the tunnel axis in order to simplify the analysis.

3.2.1. Influence of the Tunnel Depth on the Lateral and Longitudinal Temperature Fields in the Tunnel. The temperature variation in the tunnel with the tunnel depth was obtained from equations (14) and (20). As seen in
Figure 4(a), the average annual temperature variation trends of tunnels under different cover depths are basically identical, which indicates that the cover depth of the tunnel has little influence on the antifreezing disease length of the tunnel. However, no matter how much the cover depth increases, the longitudinal temperature field in the tunnel lining within $200 \mathrm{~m}$ from the tunnel opening was affected under the action of the freeze-thaw cycle due to the low external temperature. By considering the temperature within $600 \mathrm{~m}$ from tunnel opening as an example, it is found that the higher the cover depth, the higher the average air temperature in the tunnel. It can be concluded from Figure 4(b) that the greater the cover depth of a permafrost tunnel, the lower the annual average air temperature in the tunnel. The relationship between the cover depth and the average air temperature in the tunnel is linear in the same tunnel section.

\subsubsection{Influence of the Tunnel Diameter on the Longitudinal} Temperature Field of the Tunnel. The relationship of the average air temperature function, $H(z)$, and the temperature amplitude function, $K(z)$, along the tunnel axis under different tunnel diameters is shown in Figure 5. It was also found in Figure 5(a) that the average air temperature function, $H(z)$, in the tunnel was little affected by the tunnel length under $3.0 \mathrm{~m}, 3.5 \mathrm{~m}, 4.0 \mathrm{~m}$, and $4.5 \mathrm{~m}$. In contrast, the temperature amplitude function, $K(z)$, of the air temperature in the tunnel has close relationship with the tunnel length under different tunnel diameters. The larger the tunnel diameter, the more obvious the temperature change in the tunnel, as shown in Figure 5(b).

From Figure 5, the tunnel diameter size affects the temperature distribution inside the tunnel. The smaller the tunnel radius, the closer the annual average air temperature in the tunnel that tends to be stable. In addition, the antifreeze disease length of the tunnel is also shorter. Furthermore, the average air temperature function, $H(z)$, has little relationship with the tunnel length, while the temperature amplitude function, $K(z)$, has close relationship with the tunnel length.

\subsubsection{Influence of the Insulation Layer Parameters on the} Longitudinal Temperature Field of the Tunnel. The longitudinal annual average air temperature distribution trend of the tunnel shown in Figure 6 was obtained using equations (20) and (21). The longitudinal annual average air temperature distribution characteristic of function $H(z)$ in the tunnel under the insulation coefficients of $0 \mathrm{~W} /\left(\mathrm{m} \cdot{ }^{\circ} \mathrm{C}\right)$, $0.01 \mathrm{~W} /\left(\mathrm{m} \cdot{ }^{\circ} \mathrm{C}\right), 0.03 \mathrm{~W} /\left(\mathrm{m} \cdot{ }^{\circ} \mathrm{C}\right)$, and $0.1 \mathrm{~W} /\left(\mathrm{m} \cdot{ }^{\circ} \mathrm{C}\right)$ is shown in Figure 6.

It can be seen in Figure 6 that the insulation layer arranged in the permafrost tunnel has a significant influence on the longitudinal temperature distribution of the tunnel. The insulation layer can reduce the influence of temperature inside the tunnel on the surrounding rock temperature around the tunnel lining and ensure the stability of the surrounding rock. However, as seen in Figure 6, the heat transfer coefficient of the insulation layer also affects the 
TABLE 3: Relevant parameters of the Fenghuoshan tunnel.

\begin{tabular}{lc}
\hline Related parameters & Parameter value \\
\hline Heat transfer coefficient of the surrounding rock $\left(\mathrm{m} \cdot{ }^{\circ} \mathrm{C}\right)$ & 1.650 \\
Heat capacity of the surrounding rock $\left(\mathrm{J} / \mathrm{m}^{3} \cdot{ }^{\circ} \mathrm{C}\right)$ & 2465 \\
Heat transfer coefficient of the shotcrete $\left(\mathrm{W} /\left(\mathrm{m} \cdot{ }^{\circ} \mathrm{C}\right)\right)$ & 1.655 \\
Heat capacity of the shotcrete $\left(\mathrm{J} / \mathrm{m}^{3} \cdot{ }^{\circ} \mathrm{C}\right)$ & $1.617 \times 10^{3}$ \\
Heat transfer capacity of the thermal insulation $\left(\mathrm{W} /\left(\mathrm{m} \cdot{ }^{\circ} \mathrm{C}\right)\right)$ & 0.003 \\
Heat capacity of the insulation $\left(\mathrm{J} / \mathrm{m}^{3} \cdot{ }^{\circ} \mathrm{C}\right)$ & $0.072 \times 10^{3}$ \\
Heat transfer coefficient of the $\operatorname{lining}\left(\mathrm{W} /\left(\mathrm{m} \cdot{ }^{\circ} \mathrm{C}\right)\right)$ & 1.825 \\
Heat capacity of the lining $\left(\mathrm{J} / \mathrm{m}^{3} \cdot{ }^{\circ} \mathrm{C}\right)$ & $1.312 \times 10^{3}$ \\
Air speed $(\mathrm{m} / \mathrm{s})$ & 0.3 \\
Air heat transfer coefficient $\left(\mathrm{W} /\left(\mathrm{m} \cdot{ }^{\circ} \mathrm{C}\right)\right)$ & 0.02 \\
Freezing and thawing depth around the surrounding rock $(\mathrm{m})$ & 10 \\
Heat transfer coefficient between the air and the surrounding rock $\left(\mathrm{W} /\left(\mathrm{m} \cdot{ }^{\circ} \mathrm{C}\right)\right)$ & 20 \\
\hline
\end{tabular}

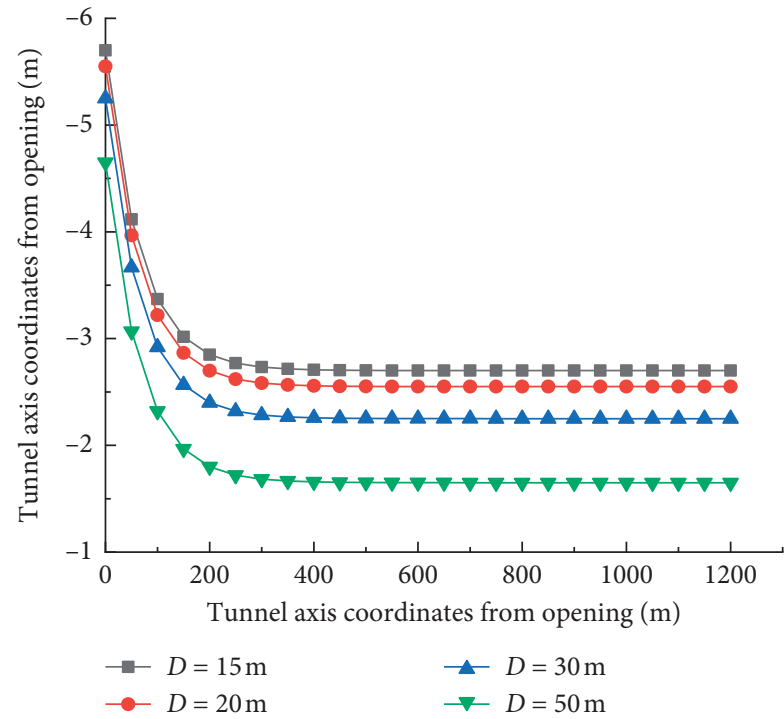

(a)

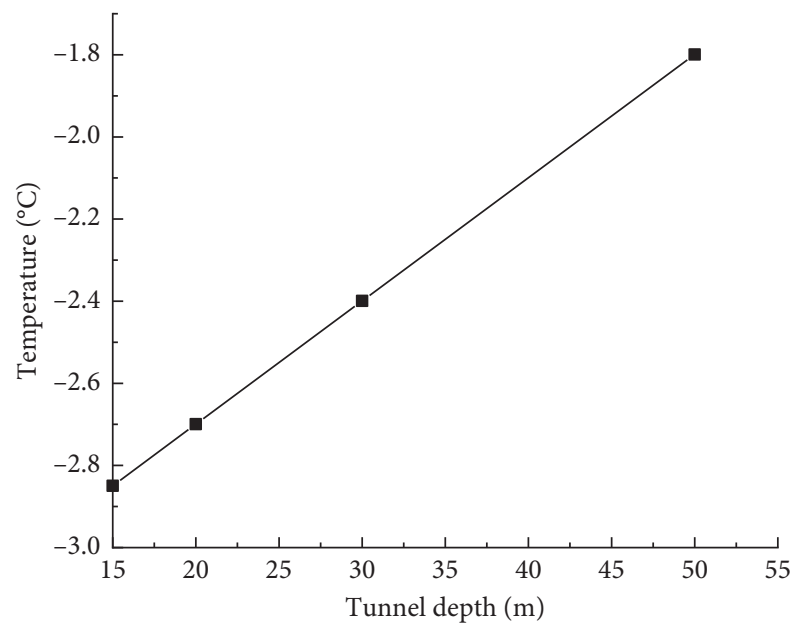

(b)

FIgURE 4: The annual air average temperature change curve under different tunnel depths: (a) annual longitudinal average temperature of the tunnel; (b) annual average air temperature of the same tunnel cross-section.

longitudinal temperature field distribution in the tunnel to a certain extent. After that, the change in the longitudinal temperature field distribution is not obvious in the tunnel, even if the heat transfer coefficient of the insulation layer is greater. The higher the heat transfer coefficient of the insulation layer, the nearer the position of the annual average air temperature function, $H(z)$, and it tends to be stable at the tunnel opening. At this time, the shorter the antifreezing fortification length of the tunnel is, the better the tunnel antifreezing disease fortification is. However, in terms of the temperature field distribution characteristics in the tunnel cross-section, the smaller the thermal insulation coefficient of insulation layer, the better the thermal insulation effect between the tunnel and the surrounding rock. In order to effectively carry out antifreeze protection in tunnels, the longitudinal temperature field distribution characteristics and lateral temperature field of the surrounding rock should be taken into account when setting the thermal insulation layer so as to effectively carry out the antifreeze protection for tunnels.
3.2.4. Influence of the Air Velocity in the Tunnel on the Longitudinal Temperature Field. Figure 7 shows that both the average air temperature function, $H(z)$, and the temperature amplitude function, $K(z)$, are closely related to the air velocity in the tunnel. The smaller the velocity in the tunnel, the closer the average air temperature function and the temperature amplitude function that tend to be near the location of the tunnel opening. When the air velocity in the tunnel is small enough, the average air temperature function and the temperature amplitude function in the tunnel tend to be stable. In addition, the position of the tunnel opening will be close to that of the tunnel opening. In contrast, the temperature amplitude function, $K(z)$, in Figure 7 (b) is more strongly influenced by the air velocity than the average temperature function, $H(z)$, in Figure $7(a)$.

\subsection{Theoretical Calculation of the Antifreezing Fortification} Length Based on the Closed-Form Solution. In this paper, the antifreezing fortification length in a permafrost tunnel is 


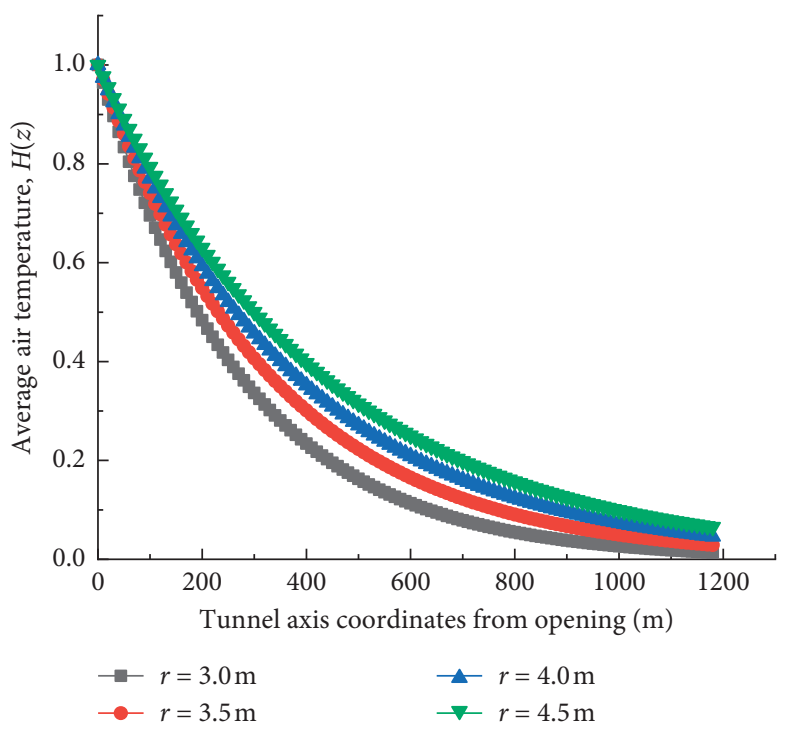

(a)

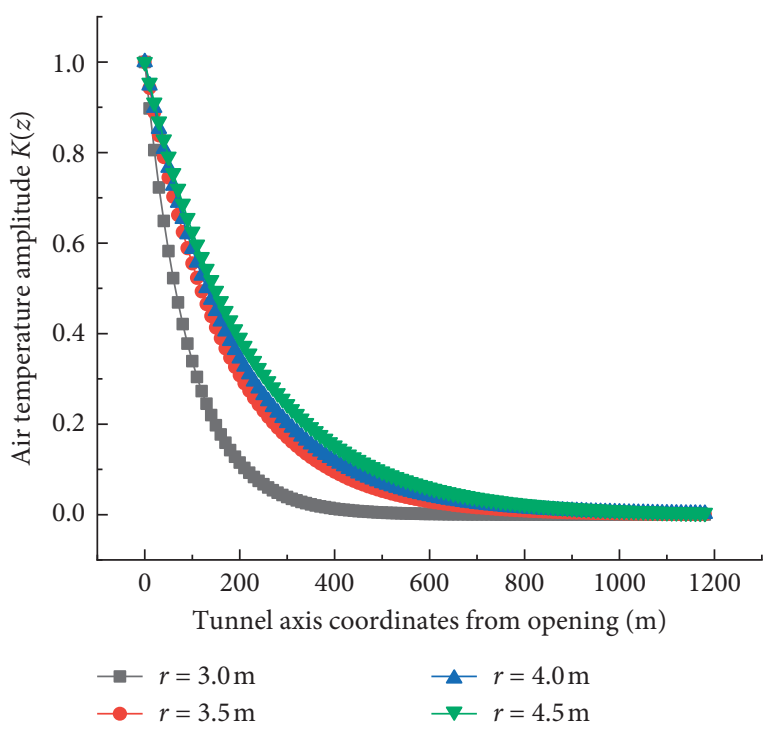

(b)

FiguRE 5: Variation of longitudinal direction temperature function with different tunnel radii: (a) the average air temperature function, $H(z)$, under tunnel length; (b) the air temperature amplitude function, $K(z)$, under tunnel length.

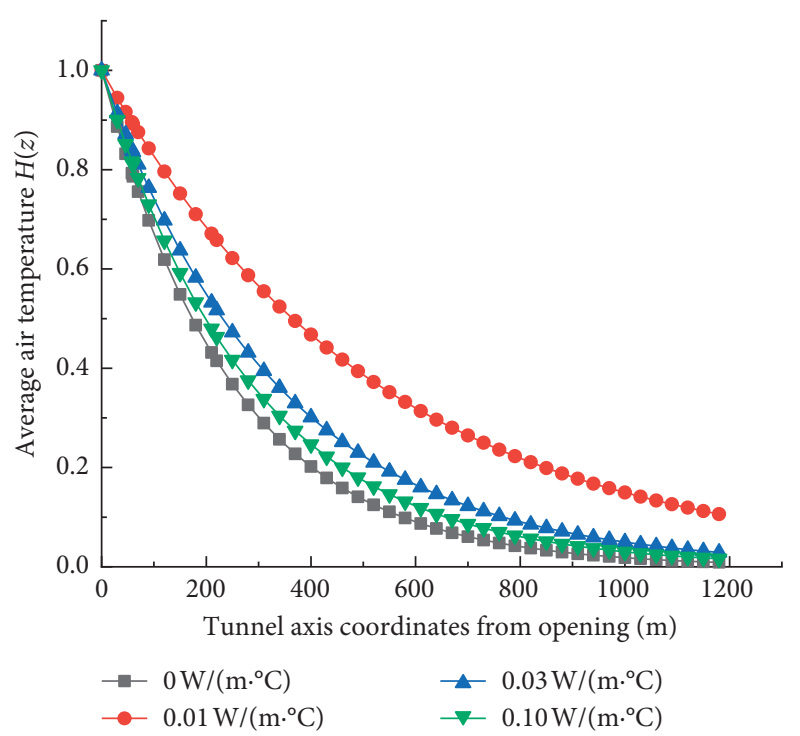

Figure 6: Comparison of the mean temperature function, $H(z)$, of the tunnel under different insulation coefficients.

determined based on the temperature distribution characteristics along the longitudinal direction of the tunnel. The temperature distribution in the tunnel is primarily determined by both the average temperature function, $H(z)$, and the temperature amplitude function, $K(z)$. The average temperature function and the temperature amplitude function are analyzed to determine the frost resistance length of a permafrost tunnel. The principle of antifreezing fortification length in permafrost tunnels is shown in Figure 8.

Based on equation (23), equation (22) was used to calculate the following temperature field variation characteristics in a tunnel, as shown in Figure 9. It can be concluded by the longitudinal average temperature amplitude distribution in Fenghuoshan tunnel that the antifreezing disease fortification length is $216 \mathrm{~m}$ away from the tunnel opening, which is approximately 31 times that of the tunnel diameter:

$$
\begin{aligned}
f(z, t)= & T_{0}+\left(T_{J}-T_{0}\right) \operatorname{EXP}(E z)+K(z) \\
& \times \operatorname{EXP}\left(-i\left(\frac{\omega}{V_{f}}+\frac{2 \alpha_{1} g_{3}\left(r_{0}\right) \cos \varphi_{3}}{V_{f} \rho c_{p} r_{0}}\right) z\right) \cos (\omega t+\varphi) .
\end{aligned}
$$

\section{Verification of the Analytical Model}

4.1. Program for the Numerical Parametric Study. As stated in the previous sections, this numerical parametric study investigates the effects of the tunnel length, the heat transfer capacity of the insulation layer, the tunnel depth, and the air velocity at the tunnel opening. All of the numerical physical parameters are summarized in Table 4. For simplicity, this study only focuses on the temperature distribution characteristics of a single tunnel with a length of $300 \mathrm{~m}$ from the tunnel opening.

4.2. Computational Model. To investigate the precision of its predictions, the analytical solution was compared to the numerical approach. The analysis was conducted by a threedimensional finite element that considered the geometry of the Fenghuo Tunnel in the Qinghai-Tibet Railway, as shown in Figure 10.

As shown in Figure 11, the heat transfer model between the lining and the insulation layer and the lining and the surrounding rock in the permafrost tunnel was adopted. The heat transfer model between the air and the lining used a 


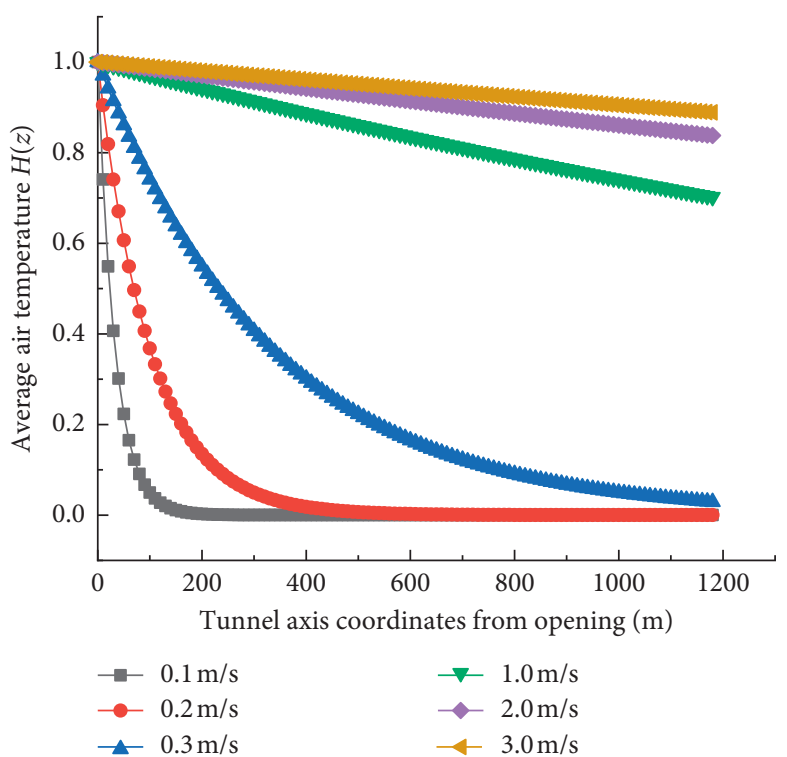

(a)

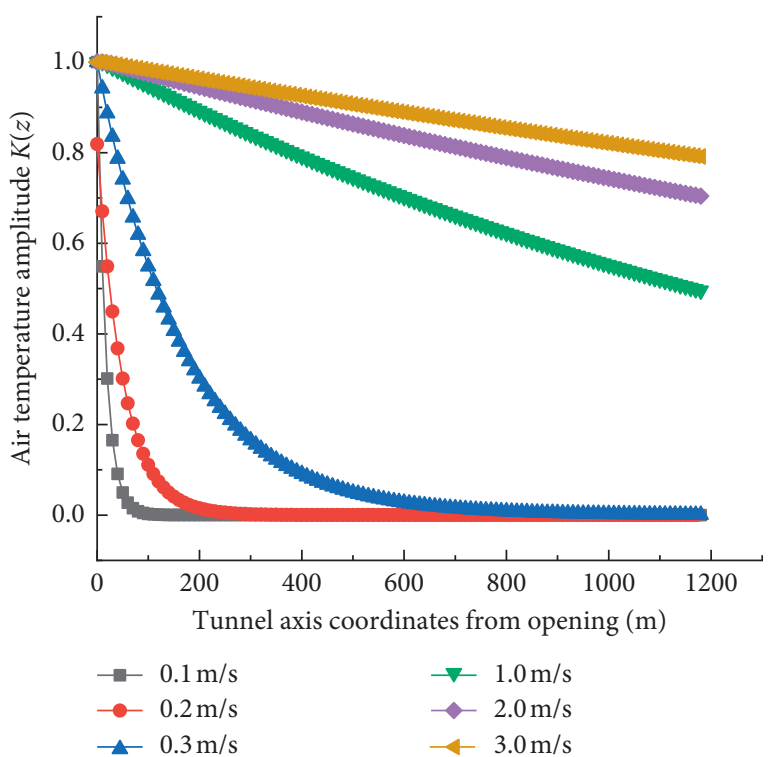

(b)

Figure 7: Temperature variation curve in the longitudinal direction under different velocities: (a) the average temperature function, $H(z)$, in the tunnel; (b) the temperature amplitude function, $K(z)$, in the tunnel.

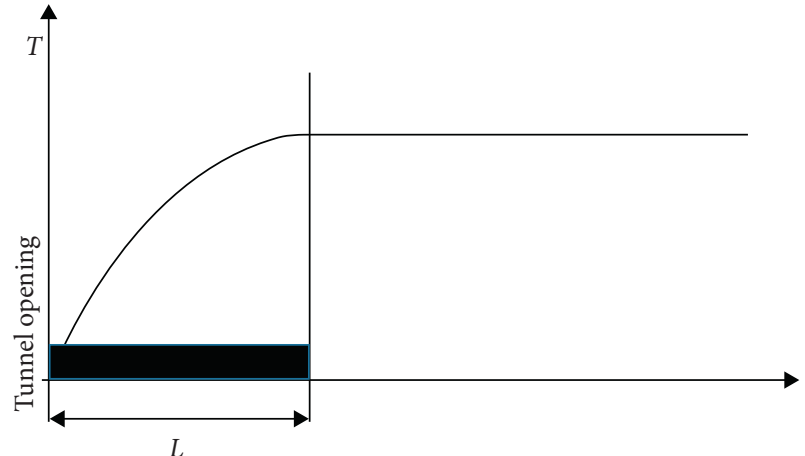

Figure 8: Design of the antifreeze disease fortification length in a tunnel.

heat convection unit model, and a heat convection model between the outside temperature of the tunnel and the inside temperature of the tunnel was also used.

\subsection{Boundary Conditions and Initial Conditions}

4.3.1. Boundary Conditions. The left and right boundary conditions of the tunnel were used as the initial temperature boundary conditions based on actual conditions. The temperature of the tunnel opening was measured in the Fenghuoshan tunnel. The upper boundary of the model and the upper part of the tunnel opening were used as the heat convection boundaries between the air and the surrounding rock. In the tunnel opening, there is a convective heat transfer law between the lining and the air in the tunnel; that is, the boundary between the air and the lining in the tunnel was used as the convective heat transfer boundary. To ensure that air can flow through the tunnel wall, a boundary

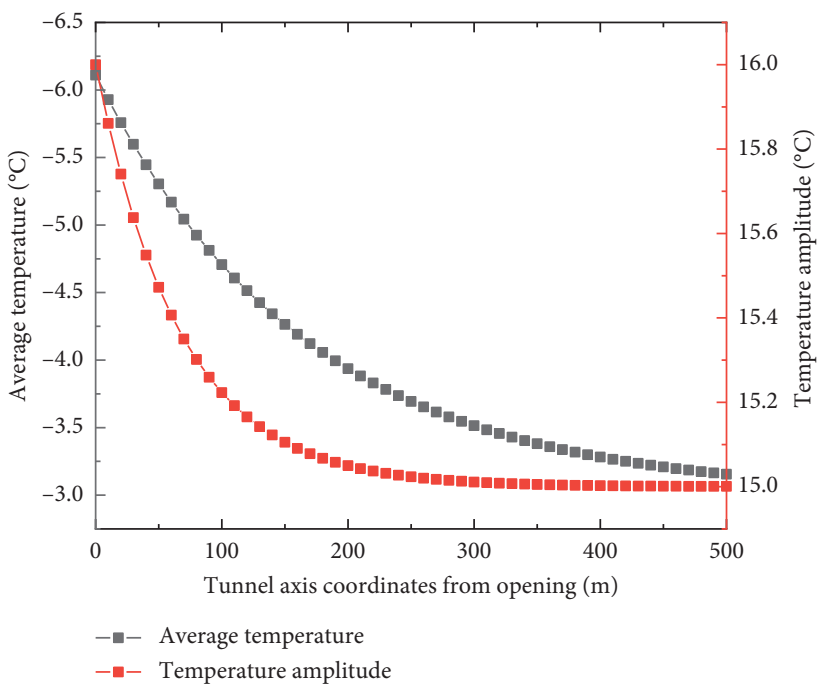

FIGURE 9: Longitudinal distribution curve of the average temperature and temperature amplitude in a tunnel.

condition of zero pressure was used on a line of the tunnel wall because it was assumed that the air in the tunnel was incompressible. At the tunnel opening, the air velocity function and the temperature function of the tunnel opening were set to simulate the boundary conditions at the tunnel opening.

4.3.2. Initial Conditions. The initial air temperature in the tunnel was $269.15 \mathrm{~K}$, and the initial air velocity was $0 \mathrm{~m} / \mathrm{s}$. The initial temperature of lining was $268.65 \mathrm{~K}$. The initial temperature of the insulation layer was $-269.15 \mathrm{~K}$. The initial temperature of the shotcrete was $268.15 \mathrm{~K}$. The average 
TABLE 4: Physical parameters of air, soil mass, lining, and insulation layer.

\begin{tabular}{lcccc}
\hline Parameters & Air & Soil mass & Lining & Insulation layer \\
\hline Specific heat capacity $C(\mathrm{~J} /(\mathrm{kg} \cdot \mathrm{K}))$ & 1004 & 2465 & 1617 & 72 \\
Thermal conductivity $\lambda(\mathrm{W} /(\mathrm{m} \cdot \mathrm{K}))$ & 0.02 & 1.650 & 1.655 & 0.03 \\
Density $\rho\left(\mathrm{kg} / \mathrm{dm}^{3}\right)$ & 0.627 & 2056 & 2400 & 40 \\
Dynamic viscous coefficient $\mu(\mathrm{kg} /(\mathrm{m} \cdot \mathrm{s}))$ & $1.85 \times 10^{-6}$ & - & - & - \\
\hline
\end{tabular}

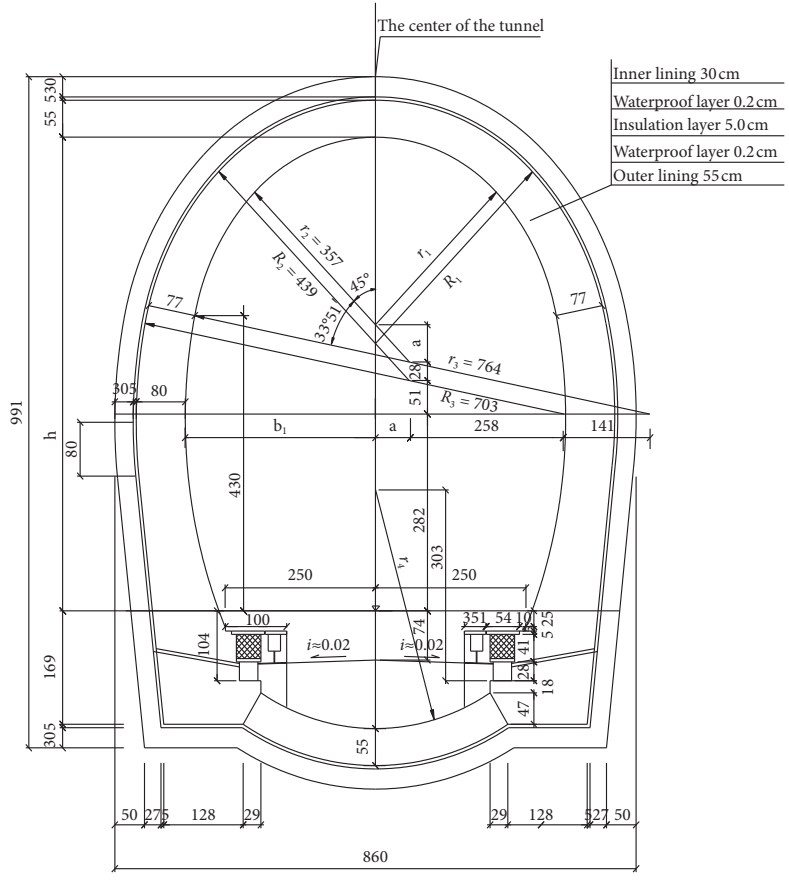

(a)

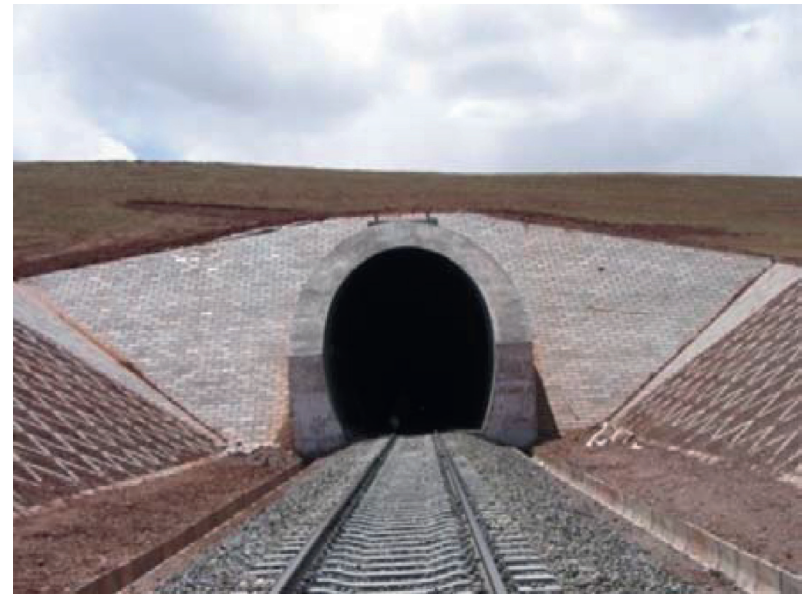

(b)

Figure 10: Cross-sectional geometry of the Fenghuo Tunnel: (a) cross-sectional structure of the schedule drawing; (b) practical engineering of the Fenghuo Tunnel.

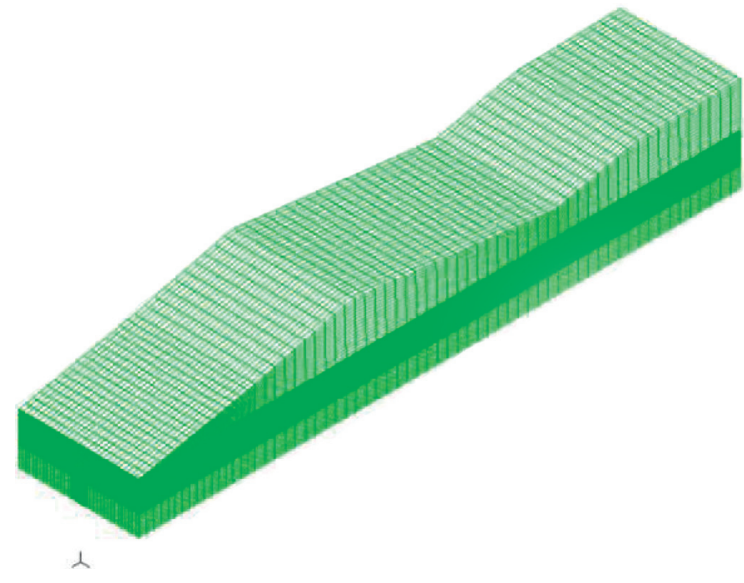

FIGURE 11: 3D mesh of the numerical model.

annual temperature at $10 \mathrm{~m}$ from the tunnel wall was $268.15 \mathrm{~K}$, and the initial temperature of the surrounding rock was obtained by increasing the temperature of the frozen soil by $2.5 \%$ [1]. The geothermal heat flux under the numerical model was $0.06 \mathrm{~W} / \mathrm{m}^{2}$.
4.3.3. Temperature Load and Air Velocity Load of the Tunnel Opening and the Mountain Top. The tunnel opening has the effect of temperature load all year round. In the numerical simulation, the actual temperature load conditions of the tunnel with time variations were set at the opening without considering climate warming. According to the temperature variation at the opening of Fenghuoshan tunnel monitored in permafrost tunnels, the following temperature load conditions were obtained:

$$
T_{d}=267.04+12 \sin (0.00072 t+0.5338),
$$

where $t$ is the number of days, unit D.

The temperature loading conditions on the mountain top of Fenghuoshan tunnel was

$$
T_{s}=269.54+12 \sin (0.00072 t+0.5338) \text {. }
$$

In order to study the influence of the velocity of the tunnel opening on the longitudinal temperature field, the characteristics of the longitudinal temperature distribution in the tunnel under the velocities at the tunnel entrance of $2.5 \mathrm{~m} / \mathrm{s}, 3.0 \mathrm{~m} / \mathrm{s}$, and $3.5 \mathrm{~m} / \mathrm{s}$ were analyzed using finite element software. 


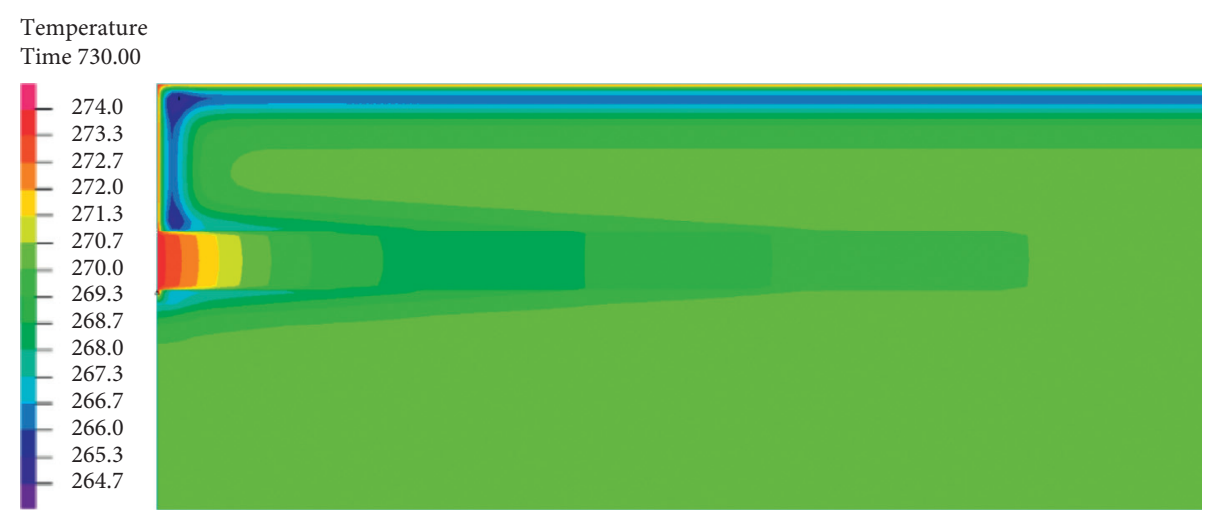

Figure 12: Average temperature distribution inside a tunnel with a $300 \mathrm{~m}$ length.

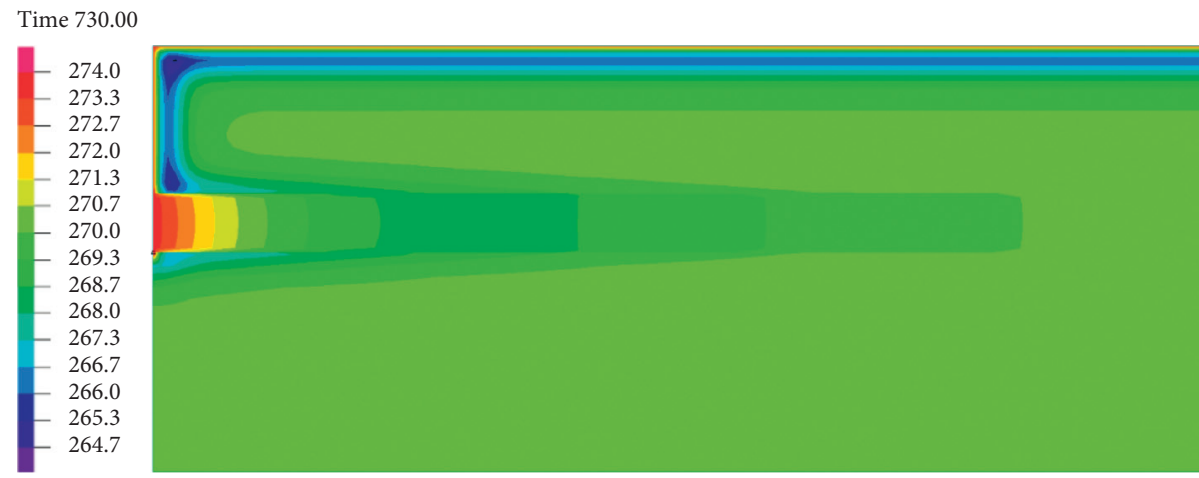

Figure 13: Average temperature distribution inside a tunnel with a $500 \mathrm{~m}$ length.

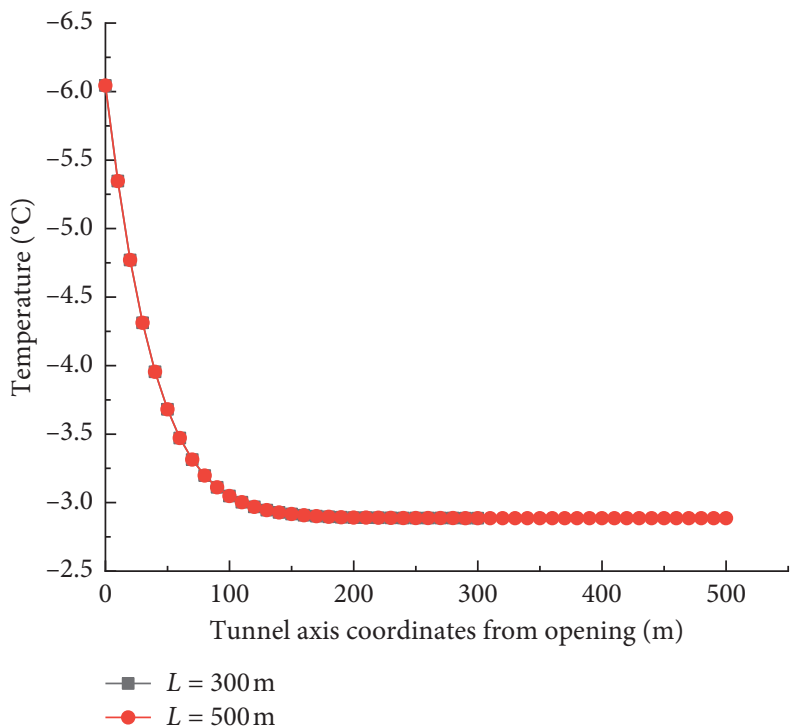

Figure 14: Longitudinal average temperature distribution characteristic curve of the tunnel.

\subsection{Discussion and Analysis of the Computed Results}

4.4.1. Effects of Tunnel Length on the Antifreezing Fortification Length. To ensure the accuracy of the numerical simulation, the height of the model was $17 \mathrm{~m}$, and the width of the model was $26 \mathrm{~m}$. In the longitudinal direction of the tunnel, the antifreezing fortification length was considered in the numerical calculation. According to the above theoretical calculation, the length of frost resistance of permafrost tunnel was found to be $200-220 \mathrm{~m}$. To select a reasonable calculation length for the tunnel, the finite element software ADINA was used to calculate the temperature distribution in tunnels under other conditions. The effects of different tunnel lengths on the 


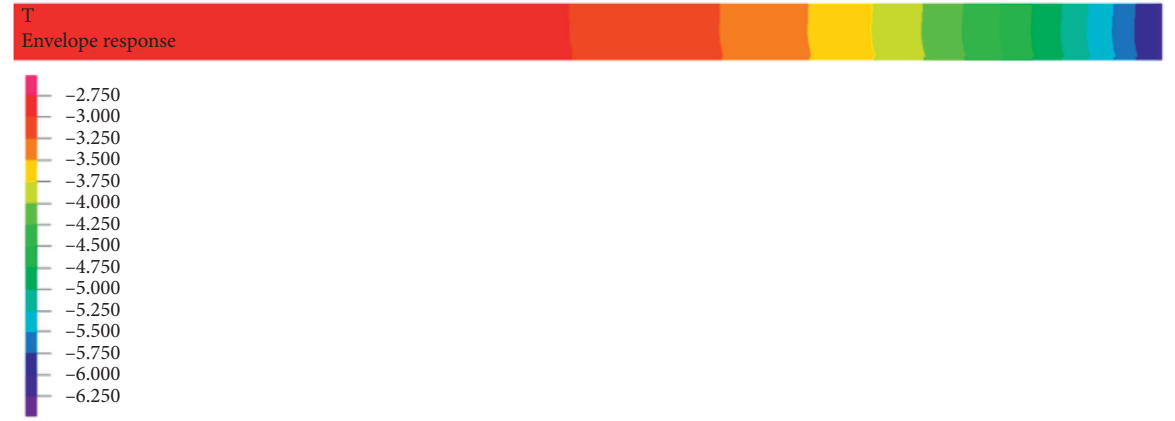

Figure 15: Annual average air temperature distribution in the tunnel axis with a thermal conductivity of $0 \mathrm{~W} /\left(\mathrm{m} \cdot{ }^{\circ} \mathrm{C}\right)$.

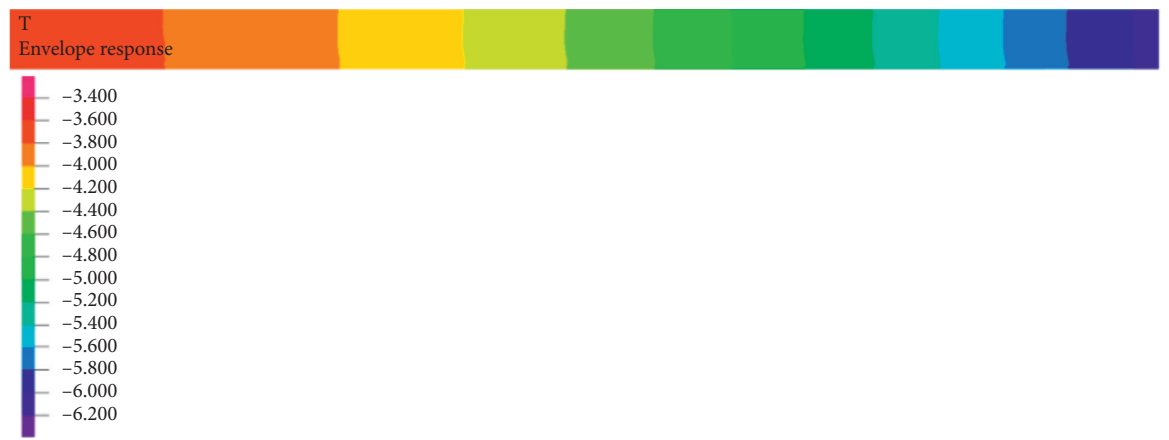

FIGURE 16: Annual average air temperature distribution in the tunnel axis with a thermal conductivity of $0.01 \mathrm{~W} /\left(\mathrm{m} \cdot{ }^{\circ} \mathrm{C}\right)$.

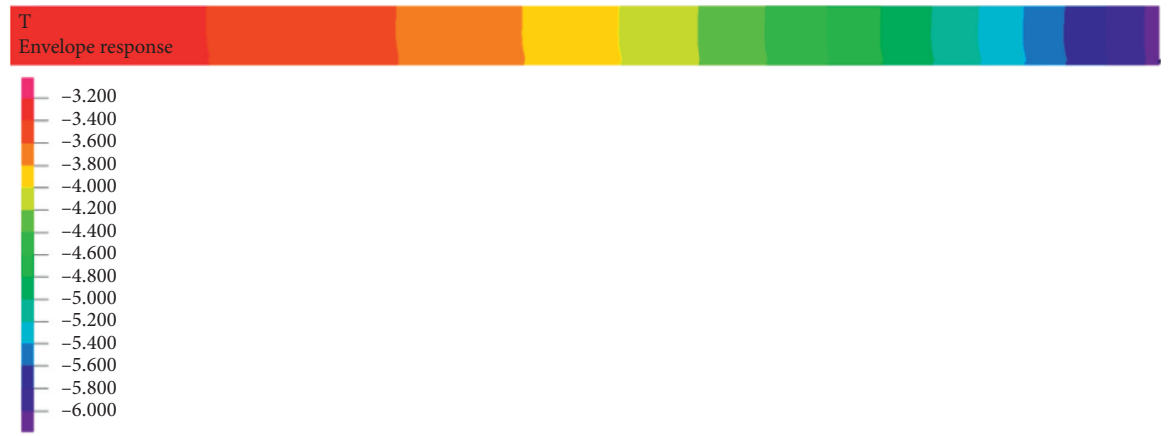

FIGURE 17: Annual average air temperature distribution in the tunnel axis with a thermal conductivity of $0.02 \mathrm{~W} /\left(\mathrm{m} \cdot{ }^{\circ} \mathrm{C}\right)$.

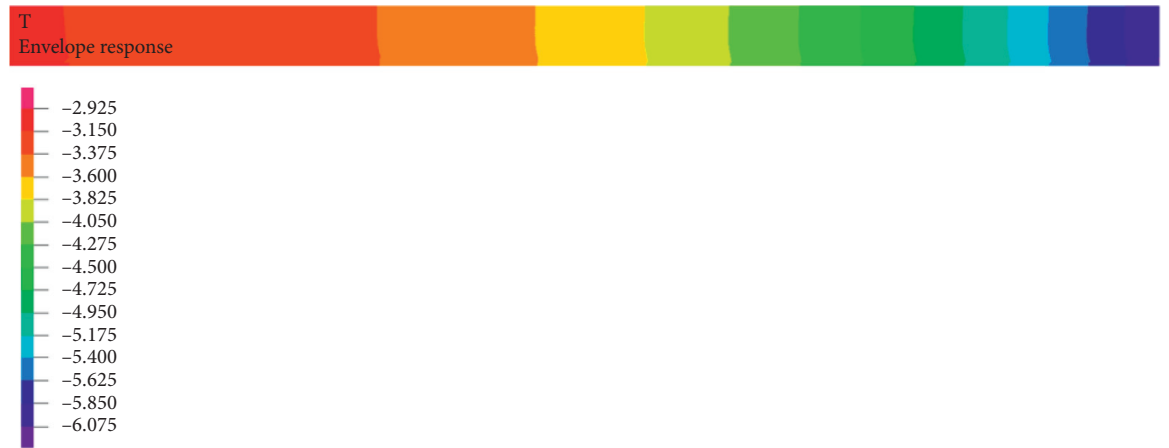

Figure 18: Annual average air temperature distribution in the tunnel axis with a thermal conductivity of $0.03 \mathrm{~W} /\left(\mathrm{m} \cdot{ }^{\circ} \mathrm{C}\right)$.

temperature distribution in tunnels are shown in Figures 12 and 13. The temperature tends to be stable when the air flow reaches a certain position in the tunnel.
The air temperature in the tunnel with a length of $300 \mathrm{~m}$ is almost the same as that in a tunnel with a length of $500 \mathrm{~m}$, as shown in Figure 14. 


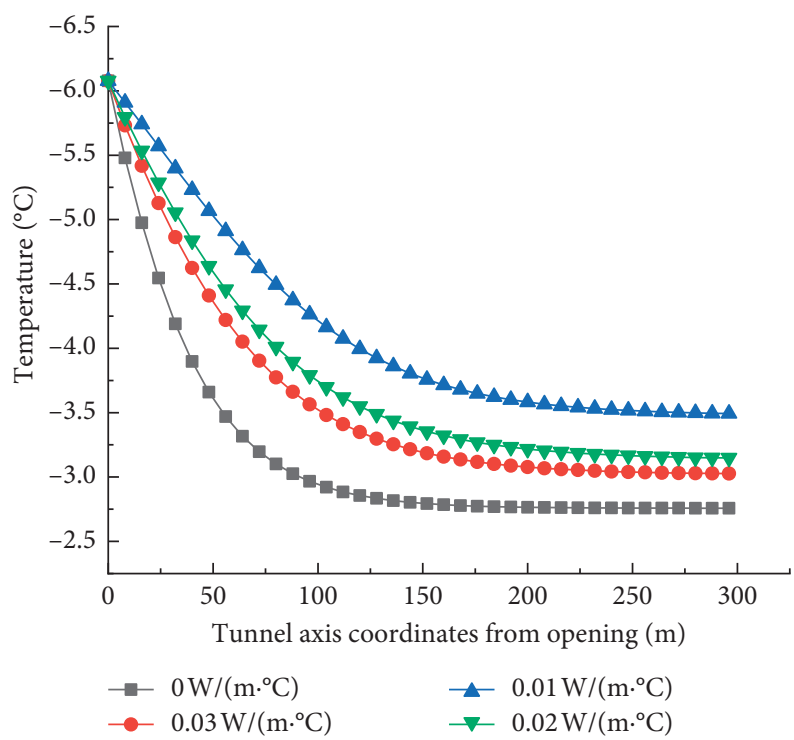

Figure 19: Distribution characteristics of the annual average air temperature inside the lining in the tunnel axis under different thermal conductivities.

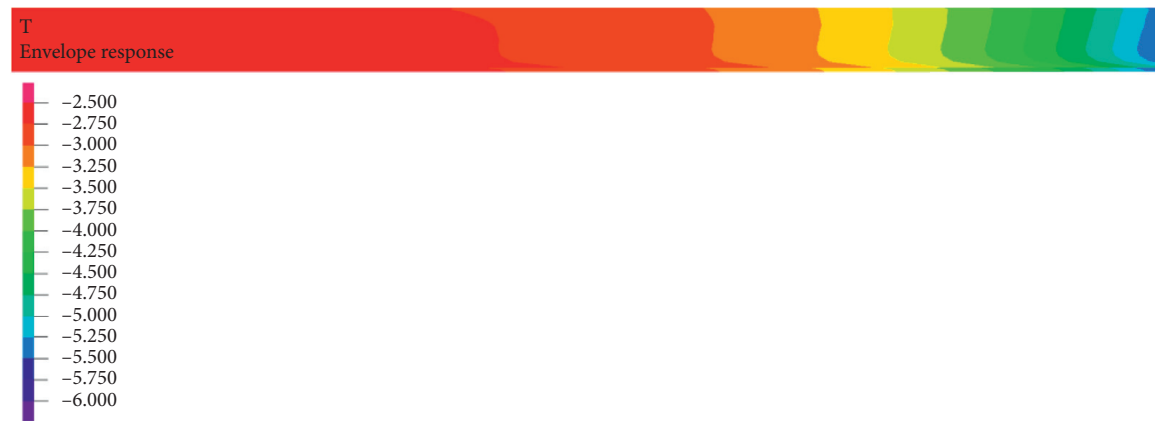

Figure 20: Annual average air temperature distribution outside the lining in the tunnel axis with a thermal conductivity of $0 \mathrm{~W} /\left(\mathrm{m} \cdot{ }^{\circ} \mathrm{C}\right)$.

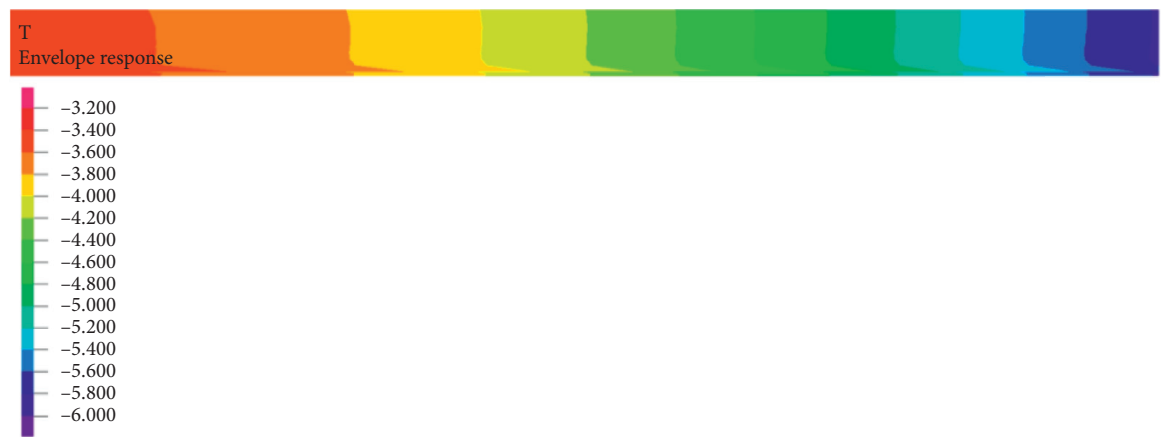

Figure 21: Annual average air temperature distribution outside the lining in the tunnel axis with a thermal conductivity of $0.01 \mathrm{~W} /\left(\mathrm{m} \cdot{ }^{\circ} \mathrm{C}\right)$.

4.4.2. Effects of Insulation Layer on the Antifreezing Fortification Length. The above theoretical analysis shows that the thermal insulation layer not only affected the temperature distribution on the cross section of the tunnel but also affected the longitudinal temperature variation characteristics of the lining wall. To verify this conclusion, the longitudinal temperature distribution characteristics in the tunnel and the lining wall under the conditions of
$0 \mathrm{~W} /\left(\mathrm{m} \cdot{ }^{\circ} \mathrm{C}\right), \quad 0.01 \mathrm{~W} /\left(\mathrm{m} \cdot{ }^{\circ} \mathrm{C}\right), \quad 0.02 \mathrm{~W} /\left(\mathrm{m} \cdot{ }^{\circ} \mathrm{C}\right)$, and $0.03 \mathrm{~W} /$ $\left(\mathrm{m} \cdot{ }^{\circ} \mathrm{C}\right)$ were studied.

Figures 15-18 show the longitudinal temperature distribution characteristics in the lining wall. Compared with the temperature inside the cave, the temperature at the tunnel opening was significantly affected by external factors. With an increase in the thermal conductivity, the tunnel length with the constant temperature also increased and 


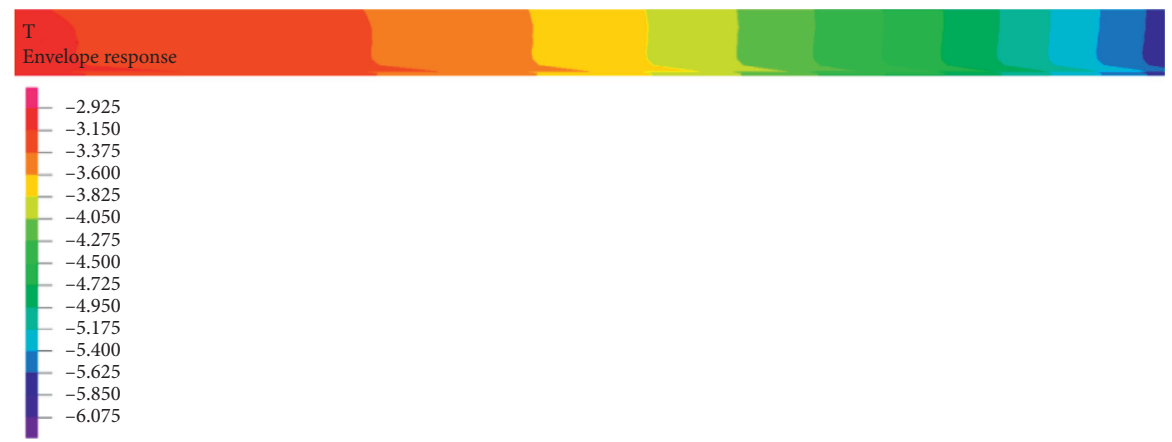

FIGURE 22: Annual average air temperature distribution outside the lining in the tunnel axis with a thermal conductivity of $0.02 \mathrm{~W} /\left(\mathrm{m} \cdot{ }^{\circ} \mathrm{C}\right)$.

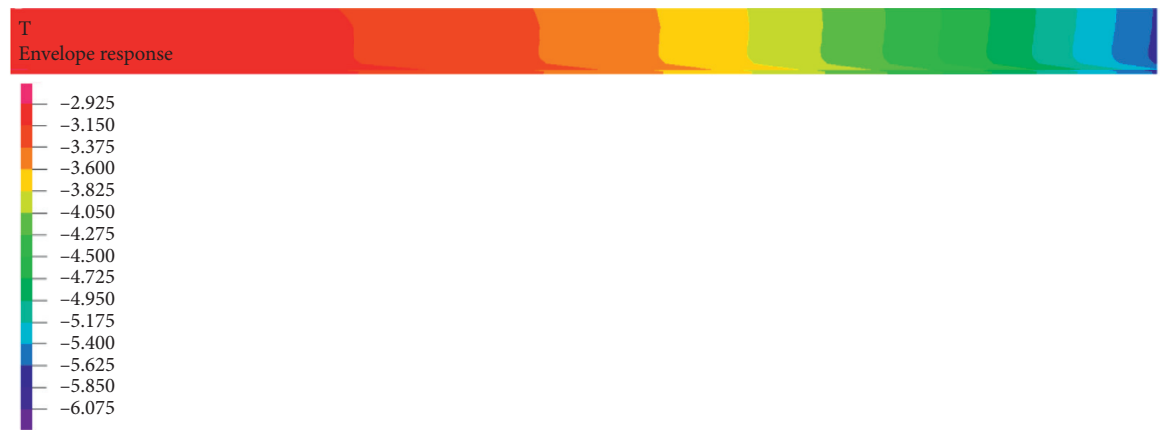

Figure 23: Annual average air temperature distribution outside the lining in the tunnel axis with a thermal conductivity of $0.03 \mathrm{~W} /\left(\mathrm{m} \cdot{ }^{\circ} \mathrm{C}\right)$.

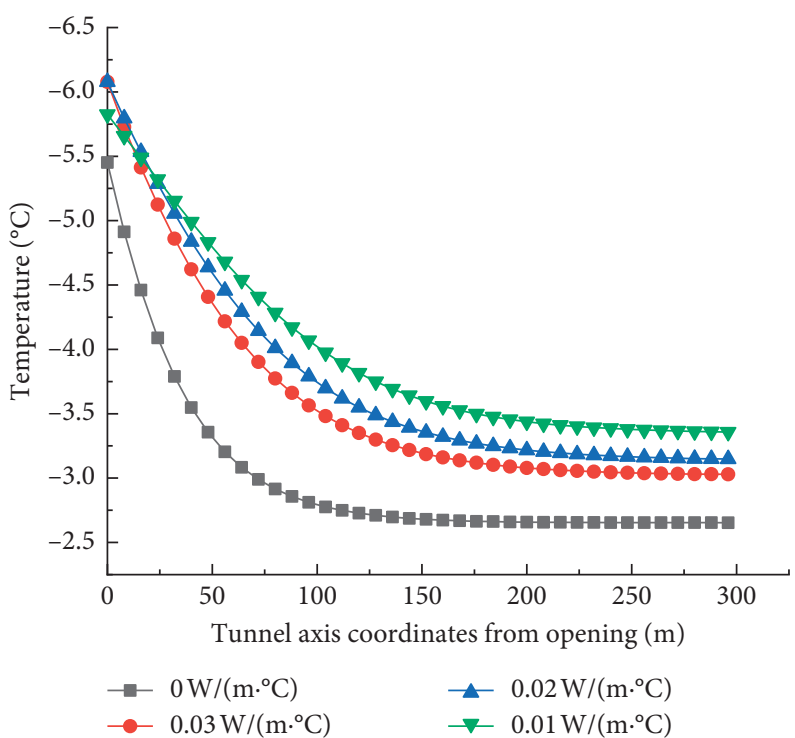

Figure 24: Distribution characteristics of the annual average air temperature vault in the tunnel axis under different thermal conductivities.

tended to be constant. In addition, the tunnel length disturbed by external temperature was approximately $200 \mathrm{~m}$ behind from tunnel opening under the conditions of $0 \mathrm{~W} /$ $\left(\mathrm{m} \cdot{ }^{\circ} \mathrm{C}\right), 0.01 \mathrm{~W} /\left(\mathrm{m} \cdot{ }^{\circ} \mathrm{C}\right), 0.02 \mathrm{~W} /\left(\mathrm{m} \cdot{ }^{\circ} \mathrm{C}\right)$, and $0.03 \mathrm{~W} /\left(\mathrm{m} \cdot{ }^{\circ} \mathrm{C}\right)$. The temperature distribution is shown in Figure 19.

Moreover, the monitoring point located behind the lining vault in Figures 20-23 indicates that the temperature distribution characteristics outside the lining in the tunnel axis were similar, as shown in Figures 15-18, despite the role of thermal insulation. The distribution characteristics of the annual air average temperature vault in the tunnel axis under different thermal conductivities, as shown in Figure 24, show that the tunnel length disturbed by external temperature was approximately $200 \mathrm{~m}$ behind the tunnel opening under the conditions of $0 \mathrm{~W} /\left(\mathrm{m} \cdot{ }^{\circ} \mathrm{C}\right), 0.01 \mathrm{~W} /\left(\mathrm{m} \cdot{ }^{\circ} \mathrm{C}\right), 0.02 \mathrm{~W} /\left(\mathrm{m} \cdot{ }^{\circ} \mathrm{C}\right)$, and $0.03 \mathrm{~W} /\left(\mathrm{m} \cdot{ }^{\circ} \mathrm{C}\right)$. The annual air average temperature distribution characteristics of both the inside lining and the outside lining in the tunnel axis under different thermal 


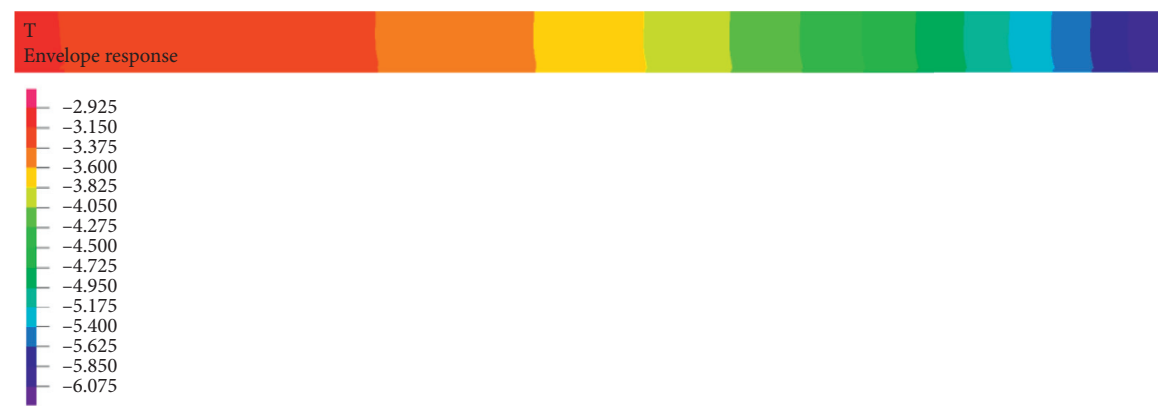

Figure 25: Annual average air temperature distribution in the tunnel axis at a depth of $20 \mathrm{~m}$.

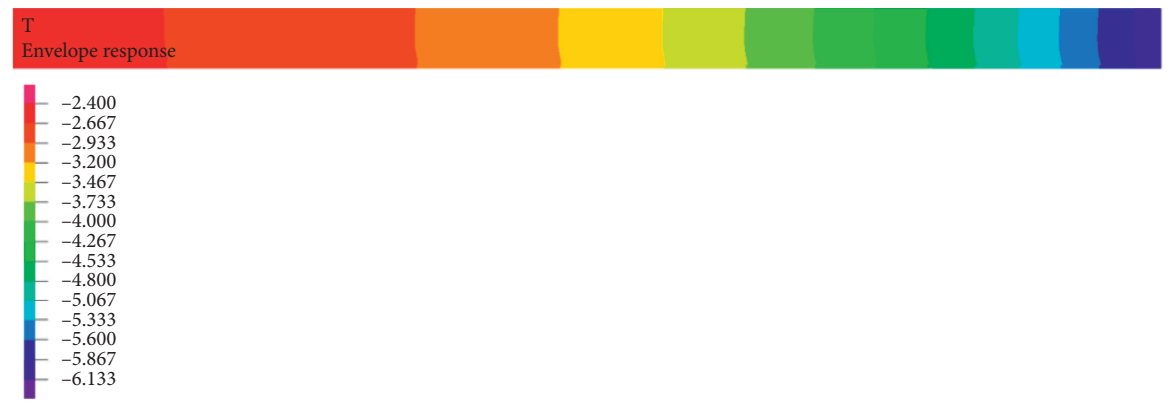

FIgURE 26: Annual average air temperature distribution in the tunnel axis at a depth of $30 \mathrm{~m}$.

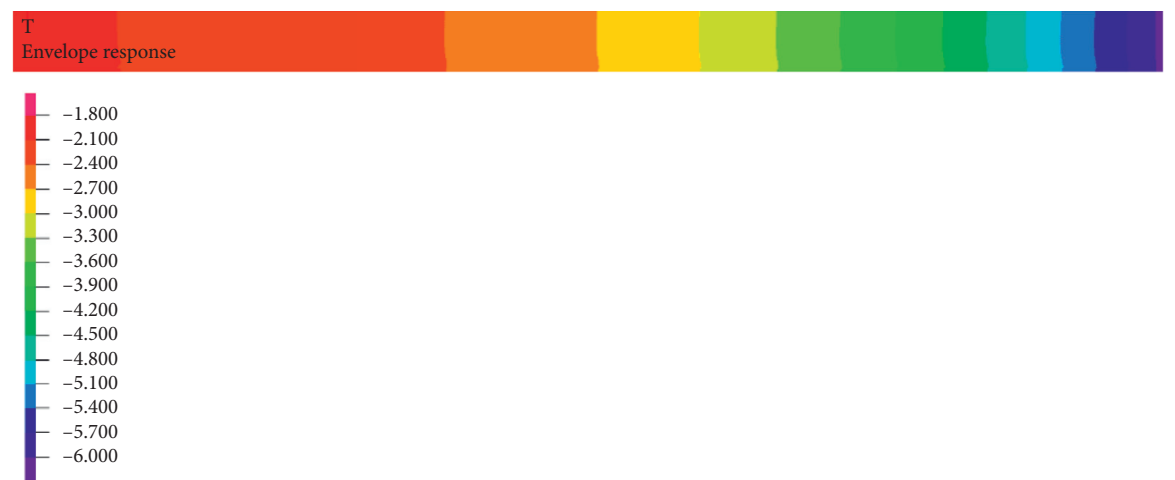

FIgURE 27: Annual average air temperature distribution in the tunnel axis at a depth of $50 \mathrm{~m}$.

conductivities are in good agreement with the calculated results of (19). A length of $200 \mathrm{~m}$ behind from tunnel opening, which is 31 times the tunnel diameter, can be regarded as the antifreeze disease fortification length.

\subsubsection{Effects of Tunnel Depth on the Antifreezing Fortification} Length. It can be seen in Figures 25-27 that the tunnel depth has little influence on the longitudinal temperature distribution trend in the tunnel. However, the tunnel depth had some influence on the tunnel length under a constant temperature. The deeper the tunnel depth, the higher the temperature tended to be stable. At a length of $200 \mathrm{~m}$ behind the tunnel opening, the temperature was the same as that of the theoretical calculation, as shown in Figure 28.

4.4.4. Effects of Velocity at Tunnel Opening on the Antifreezing Fortification Length. The theoretical analysis method was used to analyze the annual temperature distribution characteristics of the tunnel wall in the axial direction of the tunnel under different wind speeds. The smaller the wind speed, the smaller the turbulent temperature length in the tunnel, as shown in Figures 29-31. To verify this conclusion, the antifreeze disease fortification length of the Fenghuoshan tunnel was obtained using a numerical simulation. According to the velocity load range at the opening of the Fenghuoshan tunnel in Figure 32, the temperature distribution characteristics of permafrost tunnels were analyzed under different air velocities of $2.5 \mathrm{~m} / \mathrm{s}$, $3.0 \mathrm{~m} / \mathrm{s}$, and $3.5 \mathrm{~m} / \mathrm{s}$ at tunnel opening.

4.5. Antifreeze Disease Fortification Length of Fenghuoshan Tunnel. To obtain the antifreezing disease fortification length of the Fenghuoshan tunnel, the 3D numerical model shown in Figure 11 was used to analyze the annual air 


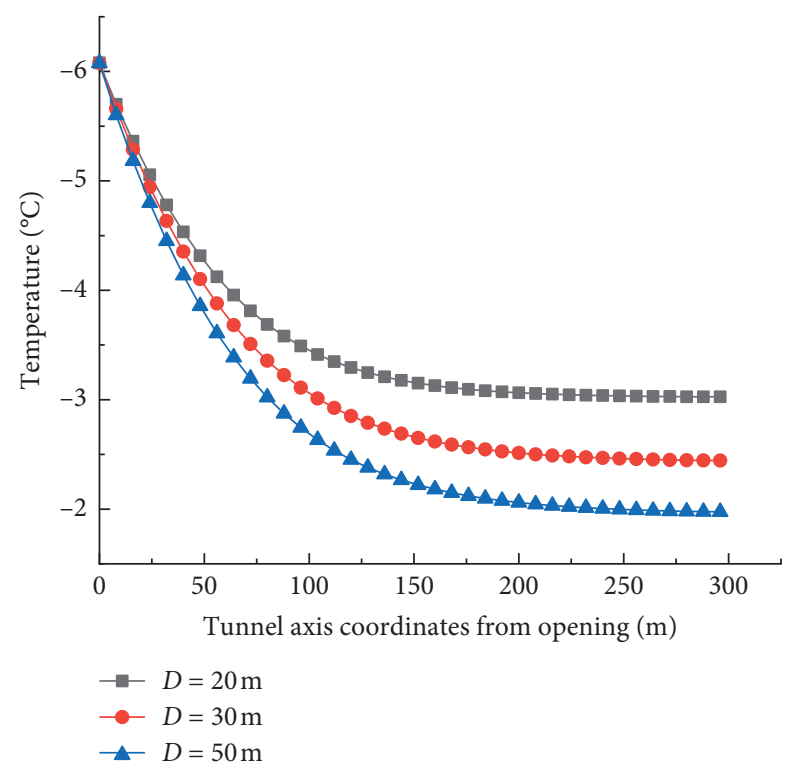

FIGURE 28: Distribution characteristics of the annual average air temperature in the tunnel axis under different depths.

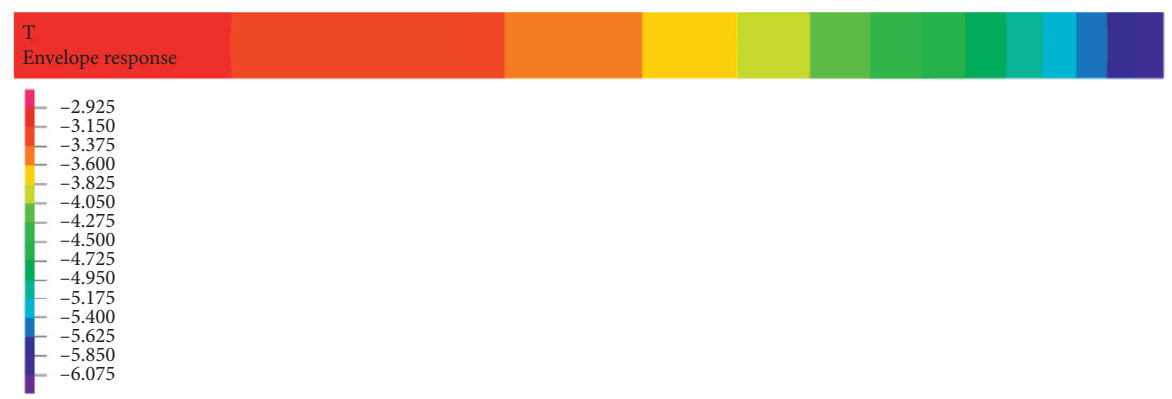

Figure 29: Annual average air temperature distribution in the tunnel axis at an air velocity of $2.5 \mathrm{~m} / \mathrm{s}$.

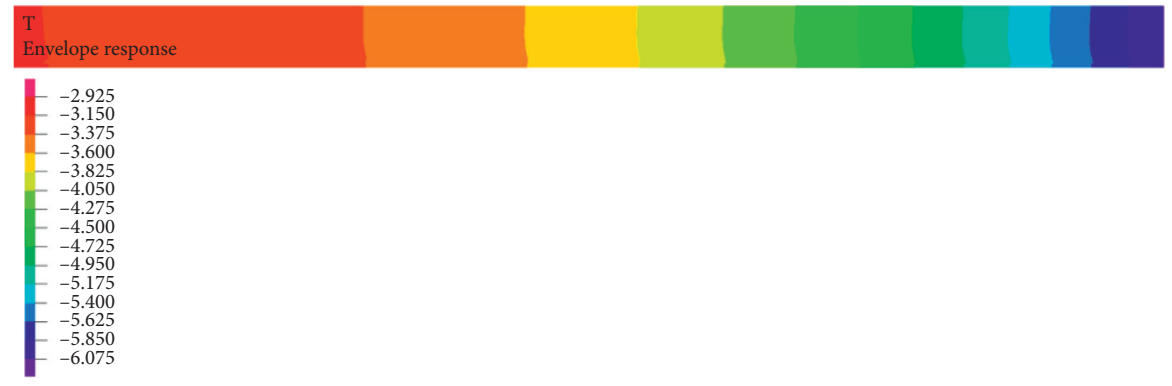

FIGURE 30: Annual average air temperature distribution in the tunnel axis at an air velocity of $3.0 \mathrm{~m} / \mathrm{s}$.

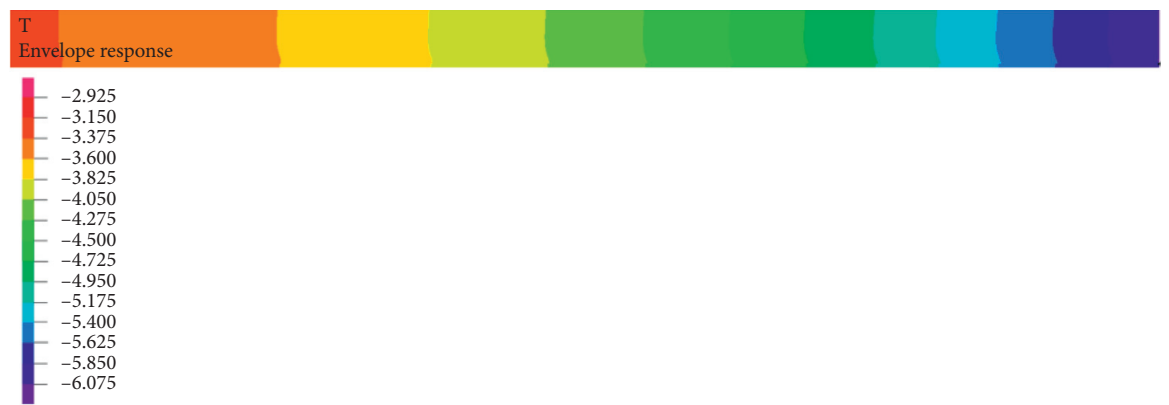

FIgURe 31: Annual average air temperature distribution in the tunnel axis at an air velocity of $3.5 \mathrm{~m} / \mathrm{s}$. 


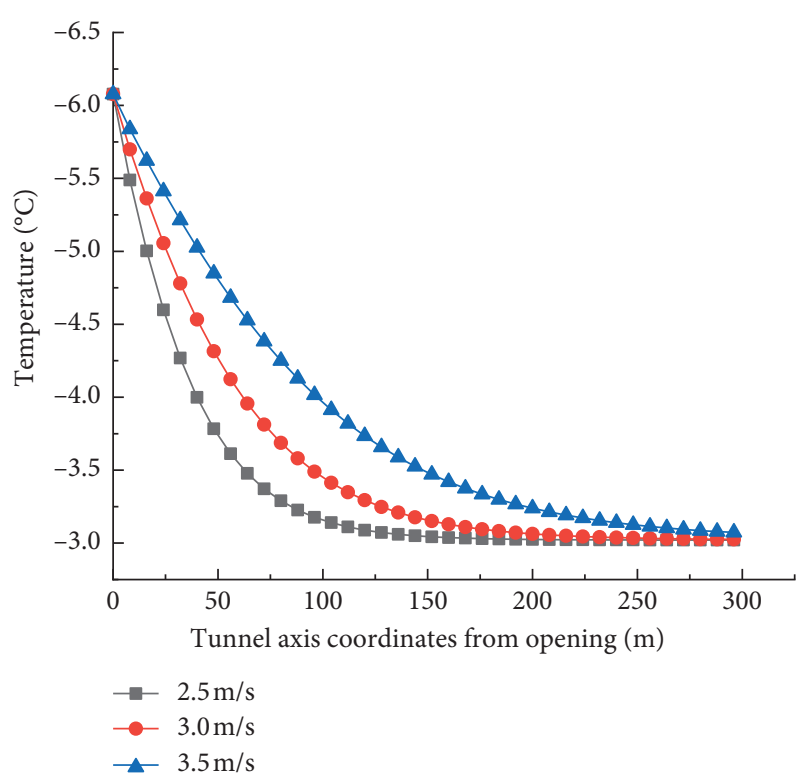

FIgURE 32: Distribution characteristics of the annual average air temperature in the tunnel axis under different air velocities.

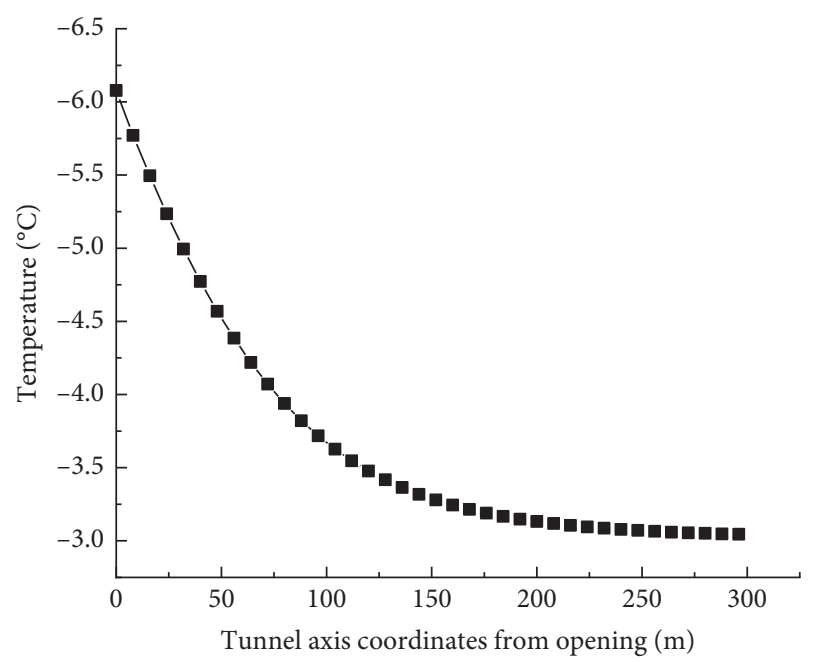

FIGURE 33: Longitudinal distribution of the average temperature in the tunnel.

average temperature distribution characteristics inside the lining at a length of $300 \mathrm{~m}$ behind the tunnel opening in the tunnel axis according to the variation in wind speeds at the Fenghuoshan tunnel opening:

$$
F(t)=0.028 \times\left(\frac{t}{30}-7\right)^{2}+2.5,
$$

where $t$ is the number of days, unit $\mathrm{D}$.

As shown in Figure 33, the average temperature in the tunnel wall tended to be more stable when it is approximately $200 \mathrm{~m}$ away from the tunnel opening than when it was approximately $200 \mathrm{~m}$ within the tunnel opening. This indicates that the temperature in the tunnel within $200 \mathrm{~m}$ from the opening varies dramatically under the influence of the external temperature. If the insulation layer is not properly set up, it will inevitably cause freezing damage of the lining, which will lead to water leakage. Therefore, the antifreezing disease fortification length obtained using the numerical simulation analysis was $200 \mathrm{~m}$, which was near to the antifreezing disease fortification length obtained using the theoretical analysis. Thus, the correctness of the theoretical analysis was verified. A length of $200 \mathrm{~m}$ from the opening can be used as a theoretical basis for the design of antifreezing fortification length of the Fenghuoshan tunnel.

\section{Conclusion}

(1) The freezing damage in permafrost tunnels is common, and this can have negative consequences for traffic. Groundwater, low temperatures, and the frost heave force are three important conditions resulting in frost damage. A certain length from the tunnel opening is the concentrated area where freezing damage occurs. Both structural design and antifreezing measures in this area need to be strengthened in permafrost tunnels. The formulas for calculating the temperature distribution characteristics along the tunnel axis were derived in this study from the heat transfer and mathematical physics equations.

(2) The effects of tunnel depth, tunnel radius, air velocity at the tunnel opening, and the thermal conductivity of the insulation layer on the temperature distribution characteristics along the tunnel axis were analyzed in detail using a theoretical calculation method. This showed that the longitudinal temperature characteristics in the tunnel axis are influenced by many factors, and it is not a function of a single factor. The Fenghuoshan tunnel was used in this study as an example. The proposed antifreezing length of the permafrost tunnel was determined to be approximately 31 times of the tunnel diameter.

(3) The greater the wind speed at the tunnel opening is, the longer the antifreezing disease fortification length becomes. The increase of insulation layer thickness was beneficial to reduce the influence of temperature in the tunnel under the freezing state of the surrounding rock, which can reduce the freezethaw damage of the tunnel lining by surrounding rock frost. However, the numerical analysis results showed that the antifreezing disease fortification length decreased significantly without the thermal insulation layer, and the freezing damage became more serious at a certain length from the tunnel opening. In addition, if the thermal insulation layer was installed, the greater the heat transfer coefficient of thermal insulation layer was, the longer the antifreezing disease fortification length was. Although the antifreezing disease fortification length increased, it can still reduce freezing damage of tunnel. The tunnel depth only affected the temperature value in the tunnel when it tended to stabilize. But it did not affect the antifreezing disease fortification length. 
(4) The numerical simulation results of the Fenghuoshan tunnel indicated that its antifreezing disease fortification length was $216 \mathrm{~m}$, approximately 31 times that of the tunnel diameter. This result was in agreement with the results of a theoretical analysis. This verifies the rationality of the theoretical calculation. The figures of 31 times of the tunnel diameter can be used as a reference for the antifreezing disease fortification length design of a tunnel.

\section{Nomenclature}

$k_{1}$ : Thermal diffusivity of lining

$k_{2}$ : Thermal diffusivity of insulation layer

$k_{3}$ : Thermal diffusivity of shotcrete

$k_{4}$ : Thermal diffusivity of surrounding rock

$T_{0}$ : Temperature in the warming zone

$T_{1}$ : Temperature of lining

$T_{2}$ : Temperature of insulation layer

$T_{3}$ : Temperature of shotcrete

$T_{\mathrm{B}}$ : Temperature in the variable temperature zone

$T_{4}$ : Temperature of surrounding rock

$T_{f}$ : Temperature of air in the tunnel

$T_{s}$ : Temperature in the tunnel wall

$T_{j}$ : Air average temperature at the tunnel opening

$r_{0}$ : Tunnel radius

$\alpha_{1}$ : Convection heat transfer coefficient of air in the tunnel

$\lambda_{1}$ : Thermal conductivity of lining

$\lambda_{2}$ : Thermal conductivity of the insulation layer

$\lambda_{3}$ : Thermal conductivity of shotcrete

$\lambda_{4}$ : Thermal conductivity of surrounding rock

$\omega$ : Temperature distribution function angular velocity

$\varphi$ : Temperature distribution function phase

$r_{1}$ : Outside radius of tunnel lining

$r_{2}$ : Radius of the tunnel insulation layer

$r_{3}$ : Radius of shotcrete

$r_{4}$ : Radius of the variable temperature zone

$H$ : Cover depth

$h_{w}$ : Influence depth of the tunnel surrounding rock

$K$ : Ground temperature gradient of the surrounding rock

$\rho: \quad$ Air density

$C_{p}:$ Air heat capacity

$M$ : Cross-sectional area of the tunnel

$G_{0}$ : Temperature amplitude at tunnel opening

\section{Data Availability}

The data used to support the findings of this study are available from the corresponding author upon request.

\section{Conflicts of Interest}

The authors declare that they have no conflicts of interest.

\section{Authors' Contributions}

Zhang Jun-wei proposed the original idea for the closedform solution for the analysis of antifreeze disease fortification length in a permafrost tunnel. Zhang Jun-wei and Yichong Zhang wrote the main manuscript text. Lei Li accomplished the numerical simulation. Bing-feng Liu prepared all the tables. Zhi-rong Mei prepared all the figures. All the authors reviewed the manuscript.

\section{Acknowledgments}

This paper was supported by the Basic Applied Research Projects of Sichuan Science and Technology Department (No. 2019YJ0349), C1 Team on Underground Space Development and Utilization of SWPU (No. X151563), and the Natural Science Foundation of China (Nos. 41702340 and 41602290).

\section{References}

[1] J.-W. Zhang, Surrounding Rock Stability and Structural Design Theory of Complex Geological Tunnels, Science Press, Beijing, China, 2019.

[2] L. Liu, Z. Li, X. Liu, and Y. Li, "Frost front research of a coldregion tunnel considering ventilation based on a physical model test," Tunnelling And Underground Space Technology, vol. 77, pp. 261-279, 2018.

[3] J. Lai, J. Qiu, H. Fan, J. Chen, and Y. Xie, "Freeze-proof method and test verification of a cold region tunnel employing electric heat tracing," Tunnelling And Underground Space Technology, vol. 60, pp. 56-65, 2016.

[4] B. Evirgen and M. Tuncan, "A physical soil freezing model for laboratory applications," Cold Regions Science and Technology, vol. 159, pp. 29-39, 2019.

[5] L. Yuan-ming, L. Song-yu, and W. Zi-wang, "Nonlinear analysis of the coupling problem of temperature field, seepage field and stress field in retaining wall of cold area," Chinese Journal of Civil Engineering, vol. 6, pp. 88-95, 2003.

[6] L. Zhi-chun, L. Wen-jiang, Z. Yong-quan, and F. Chengming, "Measurement and analysis of temperature inside and outside the tunnel of Fenghuoshan tunnel on Qinghai-Tibet Railway," Railway Standard Design, vol. 221, no. 11, pp. 56-58, 2004.

[7] J. X. Chen and Y. B. Luo, "Calculation method of antifreeze insulation thickness of tunnel in cold area," Journal of Traffic and Transportation Engineering, vol. 7, no. 2, pp. 76-79, 2007.

[8] F. Kang, S. He, B. Jiang, and F. Qi, "Detection and analysis of tunnel defects with geological penetrating radar at fenghuo mountain," Journal of Engineering Geology, vol. 18, no. 6, pp. 963-970, 2010.

[9] Y. Chao, L. Shu-chen, L. Shi-cai, and L. Wen-ting, "Study of defects characteristics and repair methods of old tunnel in cold region," Chinese Journal of Rock Mechanics and Engineering, vol. 30, no. S1, pp. 3354-3361, 2011.

[10] Y. Zhou, X. Zhang, and J. Deng, "A mathematical optimization model of insulation layer's parameters in seasonally frozen tunnel engineering," Cold Regions Science And Technology, vol. 101, pp. 73-80, 2014.

[11] R. E. Grimm and D. E. Stillman, "Field test of detection and characterisation of subsurface ice using broadband spectralinduced polarisation," Permafrost And Periglacial Processes, vol. 26, no. 1, pp. 28-38, 2015.

[12] S. Shen, C. Xia, J. Huang, and Y. Li, "Influence of seasonal melt layer depth on the stability of surrounding rock in permafrost regions based on the measurement," Natural Hazards, vol. 75, no. 3, pp. 2545-2557, 2015.

[13] T. Wang, G. Zhou, J. Wang, and L. Yin, "Stochastic analysis of uncertainty mechanical characteristics for surrounding rock 
and lining in cold region tunnels," Cold Regions Science And Technology, vol. 145, pp. 160-168, 2018.

[14] T. Wang, G. Zhou, J. Wang, and L. Zhou, "Stochastic analysis of uncertain thermal parameters for random thermal regime of frozen soil around a single freezing pipe," Heat And Mass Transfer, vol. 54, no. 9, pp. 2845-2852, 2018.

[15] D. Gang, Z. Jin-long, and L. Hai-qing, "Study on thermal insulation principle of wall-type lining structure in cold region tunnel," Highway Tunnel, vol. 63, no. 3, pp. 6-11, 2008.

[16] Y. Xu, Y. Song-hong, and M. Li-na, "Analysis and prediction of tunnel temperature field in seasonal frozen soil," Tunnel Construction, vol. 32, no. 1, pp. 57-60, 2012.

[17] W. Pei, W. Yu, S. Li, and J. Zhou, "A new method to model the thermal conductivity of soil-rock media in cold regions: an example from permafrost regions tunnel," Cold Regions Science and Technology, vol. 95, pp. 11-18, 2013.

[18] S. Li, F. Niu, Y. Lai, W. Pei, and W. Yu, "Optimal design of thermal insulation layer of a tunnel in permafrost regions based on coupled heat-water simulation," Applied Thermal Engineering, vol. 110, pp. 1264-1273, 2017.

[19] Q. Ma, X. Luo, Y. Lai, F. Niu, and J. Gao, "Numerical investigation on thermal insulation layer of a tunnel in seasonally frozen regions," Applied Thermal Engineering, vol. 138, pp. 280-291, 2018.

[20] Y. Yang, F. Gao, Y. Lai, and H. Cheng, "Experimental and theoretical investigations on the mechanical behavior of frozen silt," Cold Regions Science and Technology, vol. 130, pp. 59-65, 2016.

[21] X. Zhang, Z. Zhou, J. Li, Y. Zhou, and F. Han, "A physical model experiment for investigating into temperature redistribution in surrounding rock of permafrost tunnel," Cold Regions Science and Technology, vol. 151, pp. 47-52, 2018.

[22] X. Tan, W. Chen, H. Tian, and J. Cao, "Water flow and heat transport including ice/water phase change in porous media: numerical simulation and application," Cold Regions Science and Technology, vol. 68, no. 1-2, pp. 74-84, 2011.

[23] X. Tan, W. Chen, G. Wu, and J. Yang, "Numerical simulations of heat transfer with ice-water phase change occurring in porous media and application to a cold-region tunnel," Tunnelling and Underground Space Technology, vol. 38, pp. 170-179, 2013.

[24] M. Zhang, W. Pei, Y. Lai, F. Niu, and S. Li, "Numerical study of the thermal characteristics of a shallow tunnel section with a two-phase closed thermosyphon group in a permafrost region under climate warming," International Journal of Heat and Mass Transfer, vol. 104, pp. 952-963, 2017.

[25] J. Gao, Y. Lai, M. Zhang, and D. Chang, "The thermal effect of heating two-phase closed thermosyphons on the high-speed railway embankment in seasonally frozen regions," Applied Thermal Engineering, vol. 141, pp. 948-957, 2018.

[26] L. Yuan-ming, W. Zi-wang, Z. Shu-juan, Y. Wen-ding, and D. You-sheng, "Cold area tunnel insulation effect of the observation," Journal of the China Railway Society, vol. 25, no. 1, pp. 81-86, 2002.

[27] S. Li, M. Zhang, W. Pei, and Y. Lai, "Experimental and numerical simulations on heat-water-mechanics interaction mechanism in a freezing soil," Applied Thermal Engineering, vol. 132, pp. 209-220, 2018.

[28] W. Yu, Y. Lu, F. Han, Y. Liu, and X. Zhang, "Dynamic process of the thermal regime of a permafrost tunnel on Tibetan Plateau," Tunnelling And Underground Space Technology, vol. 71, pp. 159-165, 2018.
[29] T. A. Douglas and M. T. Mellon, "Sublimation of terrestrial permafrost and the implications for ice-loss processes on Mars," Nature Communications, vol. 10, no. 1, 2019.

[30] M. Karakouzian, M. Nazari-Sharabian, and M. Karami, "Effect of overburden height on hydraulic fracturing of concrete-lined pressure tunnels excavated in intact rock: a numerical study," Fluids, vol. 4, no. 112, 2019.

[31] M. Karami, A. Kabiri-Samani, M. Nazari-Sharabian, and M. Karakouzian, "Investigating the effects of transient flow in concrete-lined pressure tunnels, and developing a new analytical formula for pressure wave velocity," Tunnelling and Underground Space Technology, vol. 91, 2019.

[32] Y. Shi-ming and T. Wen-quan, Heat Transfer, Higher Education Press, Beijing, China, 2012. 